\title{
Endometrial cancer and obesity
}

DOI:

10.1111/tog. 12601

\section{Document Version}

Accepted author manuscript

Link to publication record in Manchester Research Explorer

\section{Citation for published version (APA):}

Kitson, S. J., \& Crosbie, E. J. (2019). Endometrial cancer and obesity. The Obstetrician and Gynaecologist. https://doi.org/10.1111/tog.12601

\section{Published in:}

The Obstetrician and Gynaecologist

\section{Citing this paper}

Please note that where the full-text provided on Manchester Research Explorer is the Author Accepted Manuscript or Proof version this may differ from the final Published version. If citing, it is advised that you check and use the publisher's definitive version.

\section{General rights}

Copyright and moral rights for the publications made accessible in the Research Explorer are retained by the authors and/or other copyright owners and it is a condition of accessing publications that users recognise and abide by the legal requirements associated with these rights.

\section{Takedown policy}

If you believe that this document breaches copyright please refer to the University of Manchester's Takedown Procedures [http://man.ac.uk/04Y6Bo] or contact uml.scholarlycommunications@manchester.ac.uk providing relevant details, so we can investigate your claim.

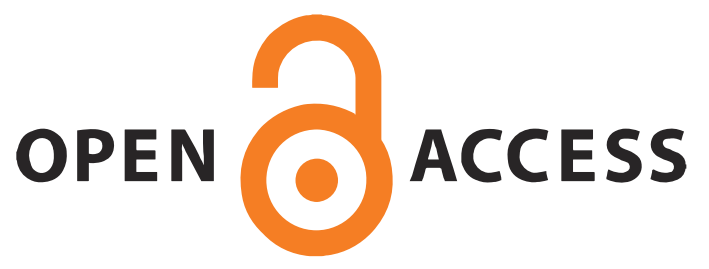




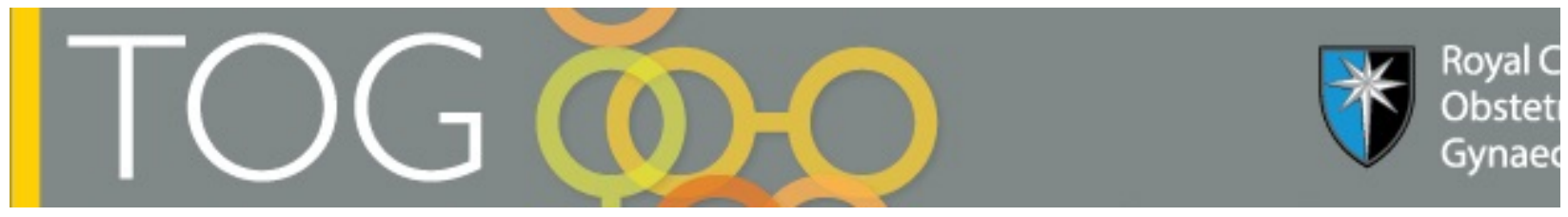

\section{Endometrial cancer and obesity}

\begin{tabular}{|c|c|}
\hline Journal: & The Obstetrician \& Gynaecologist \\
\hline Manuscript ID & TOG-18-0068.R1 \\
\hline Wiley - Manuscript type: & Reviews \\
\hline Keywords: & $\begin{array}{l}\text { Carcinoma of the endometrium, obesity, prevention, weight loss, } \\
\text { levonorgestrel-releasing intrauterine system }\end{array}$ \\
\hline Abstract: & $\begin{array}{l}\text { Key content } \\
\text { - Endometrial cancer has the strongest association with obesity of all } \\
\text { cancers } \\
\text { - Endometrial cancer should be considered in young obese women with } \\
\text { irregular and heavy menstrual bleeding } \\
\text { - Obese women should be encouraged to lose weight and to consider the } \\
\text { Mirena coil or combined oral contraceptive pill for contraception to } \\
\text { reduce their endometrial cancer risk } \\
\text { - Surgery for endometrial cancer should be performed using minimal } \\
\text { access techniques, wherever possible, to reduce the risk of post- } \\
\text { operative complications. } \\
\text { - Alternative treatments for those unfit for or who decline surgery } \\
\text { include oral or intrauterine progestins, but have lower efficacy and } \\
\text { higher relapse rates. } \\
\text { - Obesity is associated with a reduction in overall survival following } \\
\text { endometrial cancer due to cardiovascular mortality and may also impact } \\
\text { on disease specific survival. } \\
\text { - High quality, adequately powered RCTs are required to determine } \\
\text { whether weight loss following primary endometrial cancer treatment } \\
\text { improves survival. } \\
\text { Learning objectives } \\
\text { • To further understanding of the mechanisms through which obesity } \\
\text { drives endometrial carcinogenesis } \\
\text { - To improve understanding of the potential difficulties associated with } \\
\text { the management of endometrial cancer in obese women } \\
\text { - To increase knowledge of alternative treatment options for women } \\
\text { unfit for or who decline standard endometrial cancer management }\end{array}$ \\
\hline
\end{tabular}

\section{SCHOLARONE $^{\text {m }}$ Manuscripts}


Abstract

\section{$\underline{\text { Key content }}$}

- Endometrial cancer has the strongest association with obesity of the 20 most common tumour types

- Endometrial cancer should be considered in young obese women with irregular and heavy menstrual bleeding

- Obese women should be encouraged to lose weight and to consider using the Mirena coil or combined oral contraceptive pill for contraception to reduce their risk of endometrial cancer

- Surgery for endometrial cancer should be performed using minimal access techniques, wherever possible, to reduce the risk of post-operative complications. Thorough preoperative assessment and experienced surgeons are essential.

- Alternative treatments for those unfit for or who decline surgery include oral or intrauterine progestins and radiotherapy, but have lower efficacy and are associated with a higher risk of disease relapse.

- Obesity is associated with a reduction in overall survival following endometrial cancer due to an increase in cardiovascular mortality and may also impact on disease specific survival.

- High quality, adequately powered randomised controlled trials are required to determine whether weight loss following primary endometrial cancer treatment improves survival.

\section{Learning objectives}

- To further understanding of the mechanisms through which obesity drives endometrial carcinogenesis

- To improve understanding of the potential difficulties associated with the management of endometrial cancer in obese women

- To increase knowledge of alternative treatment options for women unfit for or who decline standard endometrial cancer management

\section{Ethnical issues}

- How should the increasing numbers of younger, premenopausal women with endometrial cancer be managed?

- Should super obese women with endometrial cancer only be treated in cancer centres?

- How do you counsel a woman about her weight and cardiovascular disease risk after treating her endometrial cancer?

\section{Key words}

Endometrial cancer, obesity, weight loss, levonorgestrel-releasing intrauterine system (LNG-IUS), Mirena, minimally invasive surgery, cardiovascular disease risk 


\section{Introduction}

Endometrial cancer is the most common gynaecological cancer in the UK, with over 9000 new diagnoses made every year ${ }^{(1)}$. The incidence of endometrial cancer is rising year on year (figure 1) and this trend is set to continue both in the UK and globally(2). As a consequence, endometrial cancer is expected to overtake lung and colorectal cancer to become the third most common cancer in US women by $2030^{(3)}$. Deaths from endometrial cancer are also climbing but at a slower rate (figure 1), most likely due to the preponderance of good prognosis tumours. This means that more women are now surviving endometrial cancer than ever before.

The rising incidence of endometrial cancer has been blamed on the obesity epidemic. Endometrial cancer ranks highest amongst all cancers in its association with obesity ${ }^{(4)}$. Every $5 \mathrm{~kg} / \mathrm{m}^{2}$ increase in body mass index (BMI) is linked to a $60 \%$ increase in endometrial cancer risk ${ }^{(5)}$, and this relationship is even stronger at an extreme BMI. A woman with a $\mathrm{BMI}>40$ is nearly ten times more likely to be diagnosed with endometrial cancer than a normal weight woman, giving her a lifetime risk of disease of $10-15 \%$. Such is the strength of this association that $40 \%$ of endometrial cancer diagnoses are directly attributable to obesity and ultimately preventable ${ }^{(6)}$. Obesity is related to a sedentary lifestyle and low levels of physical activity, which are also independent risk factors for the disease ${ }^{(7)}$. Obesity is most strongly linked with good prognosis type 1 (endometrioid) tumours, but its influence is also implicated in the pathogenesis of more biologically aggressive type 2 tumours ${ }^{(5)}$.

\section{Mechanisms through which obesity drives endometrial carcinogenesis}

There are three distinct, but inter-related, mechanisms through which obesity influences endometrial carcinogenesis: excess oestrogen exposure, insulin resistance and inflammation (figure 2).

Adipose tissue produces the enzymes aromatase and $17 \beta$-hydroxysteroid dehydrogenase (17 $\beta$-HSD), responsible for the conversion of the androgens androstenedione and testosterone to oestrogens oestrone and oestradiol, respectively ${ }^{(8)}$. Hyperinsulinaemia leads to a decrease in sex-hormone binding globulin (SHBG), which increases the bioavailable fraction of oestrogen. The net effect is excess oestrogen exposure without the natural counterbalance of cyclical progesterone in postmenopausal and anovulatory premenopausal women. Oestrogen drives endometrial proliferation whilst simultaneously inhibiting apoptosis. Oestrogen also promotes rapid cellular turnover through local production of insulin-like growth factor-1 (IGF-1) and, in so doing, increases the risk of accumulation of mutations in key proto-oncogenes and tumour suppressor genes ${ }^{(9)}$.

Obesity is associated with insulin resistance and chronic hyperinsulinaemia. There is now substantial in vitro evidence of a direct effect of insulin and IGF-1 on the endometrium, with activation of the insulin receptor promoting cellular proliferation and survival ${ }^{(10,11)}$. These effects are mediated through the PI3K-Akt-mTOR and MAPK pathways. Hyperinsulinaemia also increases ovarian androgen production and its peripheral aromatisation to oestrogen.

Adipose tissue expansion and its subsequent hypoxia initiates the secretion of pro-inflammatory cytokines by activated adipocytes and infiltrating macrophages, creating an inflammatory environment ${ }^{(12)}$. Activation of the NFkB pathway by inflammatory cytokines inhibits apoptosis, overrides cell cycle arrest and causes the transcription of genes encoding pro-inflammatory 
cytokines, leading to a vicious inflammatory cycle and tumourigenesis ${ }^{(13)}$. Inflammation also promotes insulin resistance, and IL- 6 stimulates aromatase activity and the conversion of testosterone to oestrogen within adipose tissue ${ }^{(14)}$.

Knowledge of these key drivers of obesity-driven endometrial carcinogenesis can facilitate the development of targeted prevention and treatment strategies.

\section{Preventing obesity-driven endometrial cancer}

Tackling obesity is a logical first step to endometrial cancer prevention ${ }^{(15)}$. Women should be encouraged to attain and maintain a normal weight as key components of living a healthy lifestyle. Obese women who lose weight through dieting have been shown to lower their serum oestrone and testosterone levels, whilst increasing insulin sensitivity and SHBG levels ${ }^{(16)}$. Current evidence suggests that endometrial cancer risk is not reduced until weight loss of at least 20lbs is achieved, however ${ }^{(17)}$.

There have been no trials of physical activity for the primary prevention of endometrial cancer, but exercise is likely to be an effective strategy through its beneficial effect on BMI. Women should be advised to undertake at least 20 minutes of moderate intensity exercise, sufficient to raise their heart rate, five times per week, similar to the recommendations for breast cancer prevention ${ }^{(18)}$. Regular physical activity reduces the risk of endometrial cancer by $20-30 \%$, with even greater benefits for those undertaking higher intensity exercise of longer duration ${ }^{(19)}$.

For morbidly obese women (i.e. those with a BMI $\geq 40 \mathrm{~kg} / \mathrm{m}^{2}$ ), bariatric surgery is an effective means of reducing endometrial cancer risk, resulting in a $70-80 \%$ lower disease risk compared with BMImatched controls ${ }^{(20,21)}$. Whilst the greatest benefit is seen in women achieving a normal body mass following surgery, even those who remain obese have a lower risk of endometrial cancer, suggesting that the effect is predominately mediated through rapid improvements in insulin sensitivity(21, 22). Whilst cancer prevention is not currently listed as an indication for bariatric surgery by the National Institute of Health and Clinical Care Excellence (NICE), eligible women should be counselled about the additional positive effects of weight loss surgery on endometrial cancer risk.

Young obese women should be advised about contraceptive choices that reduce endometrial cancer risk. Use of the levonorgestrel-releasing intrauterine system (Mirena) is associated with a $54 \%$ reduction in endometrial cancer risk, which increases to $75 \%$ if treatment is prolonged ${ }^{(23)}$. Five years or more of exposure to the combined oral contraceptive pill is effective in reducing the risk of endometrial cancer by $50 \%$, with durable protection out to 30 years post-treatment ${ }^{(24)}$, although the risks may outweigh the benefits in obese women with multiple cardiovascular risk factors. Indeed, a $\mathrm{BMl}>35 \mathrm{~kg} / \mathrm{m}^{2}$ is a relative contraindication for the combined oral contraceptive pill (UKMEC 3$)^{(25)}$.

Well-designed primary endometrial cancer prevention trials are needed to provide robust evidence for risk reducing interventions, but these will be very expensive and time-consuming. Risk prediction models that refine the population most likely to benefit from targeted prevention strategies are needed to ensure trials are adequately powered and with sufficient follow up to generate clear answers ${ }^{(26)}$.

\section{Diagnosing endometrial cancer in obese women}


Whilst the peak age incidence of endometrial cancer is $70-74$ years, there has been a $36 \%$ increase in diagnoses amongst premenopausal women over the last three decades ${ }^{(1)}$. Endometrial cancer should be considered as a potential underlying cause of persistent irregular or heavy menstrual bleeding, particularly in the context of additional risk factors like polycystic ovary syndrome (PCOS) or type 2 diabetes ${ }^{(27)}$. Premenopausal women are not considered in the updated Suspected Cancer guidance from NICE and are unlikely to undergo urgent referral for endometrial biopsy unless General Practitioners are aware of the risks ${ }^{(28)}$.

Obtaining an endometrial sample for histological assessment can be technically challenging in obese women. A Winterton speculum is longer than the average Cusco and enables complete visualisation of the cervix, particularly if used in combination with left lateral position or a colposcopy chair.

The upper weight limit of MRI scanners used in the UK varies but for very old machines, it may be as low as $125 \mathrm{~kg}$, with a maximum diameter of approximately $60 \mathrm{~cm}^{(29)}$. This may prevent some obese women from undergoing an MRI scan for staging purposes. Consideration should be given to referral to tertiary units with bariatric or open MRI machines to circumvent this issue. Alternatively, a CT scan could be performed, although this is only of use in excluding extra-uterine disease as it has lower sensitivity than MRI in determining depth of myometrial invasion and pelvic lymphadenopathy(30).

\section{Treating obese women with endometrial cancer}

\section{Surgery}

Total hysterectomy and bilateral salpingo-oophorectomy is the primary treatment for most women with endometrial cancer and is curative for those with early stage disease (limited to the uterus)(30). Gynaecologists undertaking this procedure in obese women are faced with several potential difficulties, however, including the presence of co-morbidities, including cardiovascular disease and obstructive sleep apnoea (OSA), which reduce their fitness for anaesthesia; restricted surgical access due to intra-abdominal obesity; and an increased risk of post-operative complications, particularly wound infection, if open surgery is required.

In order to allow time for pre-surgical optimisation, a thorough pre-operative assessment should be performed soon after diagnosis of endometrial cancer. This should include at least an electrocardiogram (ECG), to assess arrhythmias, echocardiography (to determine left ventricular function and the presence of valvular abnormalities) and other tests to investigate cardiac function such as an exercise stress test or cardiac MRI. The STOP-BANG questionnaire is used to screen women for OSA, with formal diagnostic testing using polysomnography (sleep study including recordings of heart rate, brain and muscle activity and eye movements) for those identified as being at high risk with a score of 3 or more (table 1$)^{(31)}$. An anaesthetic review to ensure that the woman will be able to tolerate a Trendelenburg position and to assess the need for high dependency unit post-operative care is often required.

Surgery should ideally be performed through a minimal access technique, as this has been shown to be associated with a shorter hospital stay, lower infection rate and less post-operative pain ${ }^{(32,33)}$. Importantly, the available data show no difference in survival or rates of recurrence between 
endometrial cancer patients undergoing a total laparoscopic hysterectomy compared with those treated by laparotomy ${ }^{(33,34)}$. Robotic surgery may have benefits over laparoscopy in obese women because the operating time, blood loss, hospital stay and rate of conversion to laparotomy is lower in the former group, although cost remains prohibitive for many hospital trusts ${ }^{(35-37)}$. There are currently insufficient data to inform the safest choice of surgical route in women with a BMI >50$60 \mathrm{~kg} / \mathrm{m}^{2}$, in whom conversion rates are much higher than for lean women ${ }^{(38,39)}$.

Few studies have compared the yield of pelvic and para-aortic lymph nodes in obese endometrial cancer patients undergoing different modalities of surgery, although lymphadenectomy would appear to be less frequently attempted at extremely high BMIs, by any surgical route ${ }^{(39,40)}$. If open surgery is planned, consideration could be given to combining the procedure with an apronectomy, to remove the excess skin and fat hanging over the pubic area, to improve access ${ }^{(41)}$. In rare instances where even this is not feasible, vaginal hysterectomy +/- removal of the ovaries may be performed under regional anaesthesia in those with localised endometrioid endometrial cancer ${ }^{(30)}$.

The set-up in theatre is critical to reduce the risk of intra- and post-operative complications and requires good multidisciplinary working between surgical, anaesthetic and nursing team members. This includes ensuring that the operating table is able to accommodate the patient's weight; a hover mattress is used to transfer the patient to the operating table; a beanbag or shoulder supports are used to prevent the patient slipping down the table when in head-down tilt; an open entry technique or a long veress needle is used; an adequate number and length of ports are available to make operating as ergonomic as possible; and that experienced surgeons and assistants are available to undertake the procedure. A steep Trendelenburg position is required in order to move the bowel as far as possible out of the operative field and may be aided with the use of fan retractors. The Trendelenburg position may need to be reduced episodically to avoid respiratory compromise.

\section{Radiotherapy}

Adjuvant radiotherapy reduces the rate of pelvic recurrence in women with intermediate-high risk endometrial cancer ${ }^{(42)}$. It is preferentially administered as vaginal brachytherapy, where the risk of lymph node metastases is low, as this has been demonstrated to be non-inferior to external beam radiotherapy in achieving locoregional control but is associated with fewer bladder and gastrointestinal side effects ${ }^{(43)}$. Planning and delivering radiotherapy is more difficult in obese women due to greater daily shifts and larger errors, meaning that it is harder to accurately target the radiotherapy beam and avoid non-affected tissues ${ }^{(44)}$. Greater margins are, therefore, required to achieve optimal control.

Primary radiotherapy is an alternative option for women unfit for surgery and those who are bleeding heavily. Most published data suggest that primary radiotherapy is inferior to surgery for primary disease management, being associated with a rate of recurrence of up to $18 \%{ }^{(45)}$. Combined external beam radiotherapy and intracavitary brachytherapy is associated with best locoregional control and long term outcomes, however, high dose brachytherapy alone may prove sufficient in early stage low grade endometrial cancer ${ }^{(46)}$. The accurate placement of intrauterine applicators for the delivery of brachytherapy is limited by the patient's fitness for general anaesthesia and is technically challenging at extremely high BMIs. Some centres place their intrauterine applicators under sedation or with no anaesthesia ${ }^{(47)}$, but this approach is not widely practiced or available. 
There are no RCTs comparing surgery or hormone treatment and primary radiotherapy with curative intent in endometrial cancer.

\section{Chemotherapy}

The recently published PORTEC-3 study has provided necessary evidence on which to base decisions regarding the use of chemotherapy in endometrial cancer ${ }^{(48)}$. The trial demonstrated a benefit from combined chemo-radiotherapy, using platinum and paclitaxel chemotherapy, in terms of an improvement in failure-free survival only in women with stage III disease. Adjuvant chemotherapy had no impact on survival in women with high-risk disease confined to the uterus or on overall survival.

Most morbidly obese women present with low grade, early stage disease and do not require adjuvant chemotherapy. For obese women with intermediate-high risk disease, ensuring an adequate dose of chemotherapy is challenging. The formulae used to estimate glomerular filtration rate and to dose carboplatin underestimate creatinine clearance in individuals with a large body surface area potentially resulting in the delivery of inadequate doses of the drug ${ }^{(49)}$. Obese women also have larger volumes of distribution, which can reduce target tissue drug levels, and can clear chemotherapeutics from the circulation at a different rate to leaner women, particularly if there is co-existing fatty liver disease or renal dysfunction ${ }^{(50)}$. There are, however, no clinical trial data available to guide chemotherapy dosing in obese women. Dose capping is often employed to try to prevent toxicity but may compromise clinical outcome, including progression-free and overall survival.

\section{Conservative treatment}

For women with atypical hyperplasia and low grade endometrioid endometrial cancer with minimal myoinvasion, who are either medically unfit for surgery or who decline hysterectomy because of a desire to preserve fertility, the levonorgestrel-releasing intrauterine system (LNG-IUS, Mirena, figure 3 ) or oral progestins are alternative treatment options ${ }^{(51)}$. Initial success rates of $50 \%$ and $65 \%$ have been reported for stage 1a low grade endometrial cancer and atypical hyperplasia, respectively, but recurrence rates may be as high as $25 \%$. Intrauterine progestin may have equivalent clinical efficacy to oral progestins but fewer systemic side effects $(51,52)$. There have been no randomised controlled trials comparing these treatments to standard care, with the available data on their effectiveness derived from a small number of observational studies with only limited follow-up.

Baseline imaging is important if conservative treatment is chosen. Progestin treatment is unlikely to be curative if there is >Stage 1a disease, but it may stabilise disease progression and alleviate symptoms, with benefits for quality of life, if disease is more advanced. There is a high prevalence of coincident adnexal masses in women treated conservatively for endometrial cancer, and serial imaging may be necessary to exclude sinister pathology ${ }^{(53)}$. Expert review of the index biopsy and a repeat sample taken at the time of LNG-IUS insertion/oral progestin prescription is also important to rule out rapid progression and/or high grade disease.

The optimal dose and route of progestin therapy for the conservative management of atypical hyperplasia and endometrial cancer is not known. Medroxyprogesterone acetate (MPA) 200-400mg daily in single or split doses is commonly used but is associated with weight gain, headaches and an 
increased risk of venous thromboembolic events ${ }^{(54)}$. The LNG-IUS ensures compliance and, crucially, does not cause weight gain. It can be inserted in clinic in the majority of women, even those with extremely high BMls $\left(>60-70 \mathrm{~kg} / \mathrm{m}^{2}\right)$, if a Winterton speculum and colposcopy chair are available. Around 20-30\% experience increased bleeding and pain in the first six weeks, but this is not of oncological consequence. Single agent LNG-IUS is probably sufficient if the endometrium is thickened but there is no intra-uterine mass. Resection of large intrauterine polyps prior to LNG-IUS insertion may improve response rates ${ }^{(55)}$ but large volume disease may benefit from combined treatment with both oral and intrauterine progestin, particularly if the first endometrial surveillance biopsy at 3 months does not show a marked progestin response (figure 4). There is no evidence that treatment schedules should differ according to menopausal status.

Using the 6-12 month progestin treatment window to address endometrial cancer risk factors, including obesity and insulin resistance, may improve outcomes for obese endometrial cancer patients. Weight loss may increase pathological complete response rates to progestin treatment ${ }^{(22)}$; reduce recurrence after treatment cessation; enable minimal access hysterectomy if progestin treatment fails; improve natural fecundity; enable assisted reproduction and/or improve the likelihood of its success; and improve general health and quality of life (figure 5). The ongoing ANZGOG feMME trial aims to be the first randomised controlled trial to determine the efficacy of treatment with the LNG-IUS \pm metformin \pm weight loss on pathological complete response rate in early stage endometrial cancer in obese women at six months ${ }^{(56)}$.

Follow-up of women using these alternative treatments should include an endometrial biopsy every 3 months in the first year and twice yearly thereafter to check for disease resolution, progression or recurrence. Interval MRI imaging is also recommended if surgery could be an option. Currently there are no validated biomarkers that predict treatment response ${ }^{(57)}$ and most experts opine that hysterectomy should be performed once childbearing is complete, irrespective of disease status, in those who choose to avoid hysterectomy for fertility-sparing reasons ${ }^{(30)}$.

\section{Long term outcomes in obese endometrial cancer patients}

Epidemiological studies have suggested that obesity adversely affects prognosis for endometrial cancer patients (58), but it is unclear whether this is due to an increased risk of endometrial cancerspecific death or death from other causes ${ }^{(59)}$. Endometrial cancer management is frequently suboptimal in obese women, because of the difficulties described above. This, in itself, adversely affects survival. When obese women do receive standardised treatment consistent with non-obese women, as happened in the MRC ASTEC randomised controlled trial, there is no difference in endometrial cancer-specific survival between the two groups ${ }^{(60)}$.

Whether weight loss improves endometrial cancer-specific survival is currently unknown. Studies in breast cancer have shown that weight loss reduces markers of recurrence, including total and free oestradiol, insulin, adiponectin and inflammatory and cancer-promoting proteins ${ }^{(61,62)}$. Few studies have investigated the benefits of weight loss following treatment for endometrial cancer and all have had limited follow-up, have been underpowered to examine the effect of the intervention on survival and have used diet and exercise regimes that failed to achieve substantial weight loss (63). Only one RCT reported survival at 24 months, and found no improvement in overall survival with a lifestyle and behavioural intervention. 
Achieving and maintaining clinically meaningful weight loss is extremely challenging; however, endometrial cancer may be the patient's first obesity 'symptom' and serve as an important 'teachable moment' underpinning their subsequent lifestyle choices ${ }^{(64)}$. Furthermore, the gynaecologist may be uniquely placed to deliver this teachable moment: one study found that all obese endometrial cancer survivors counselled by their gynaecological oncologist attempted weight loss, compared to just $56 \%$ counselled by their GP ${ }^{(65)}$. Successful weight loss was reported more frequently when the intervention was delivered within 6 months of endometrial cancer diagnosis ${ }^{165}$, 66).

Besides any potential impact on disease specific survival, weight loss could improve overall survival in women with a history of endometrial cancer by reducing the risk of death from other causes. Cardiovascular disease remains the commonest cause of death in women with early stage endometrial cancer, with twice as many deaths occurring from myocardial infarction, stroke and heart failure than cancer ${ }^{(67,68)}$. This is due to an increased prevalence of obesity, hypertension, hypercholesterolaemia and diabetes in endometrial cancer survivors compared with the general population and these risk factors are more likely to be undiagnosed and inadequately managed $(69,70)$. Following primary endometrial cancer treatment, women should have their blood pressure, cholesterol and $\mathrm{HbA1C}$ measured and their 10-year cardiovascular disease risk calculated using the online QRISK2 calculator (https://qrisk.org/). Cardiovascular risk factors should be optimised, including promoting weight loss, and statin therapy instituted for all women with a QRISK2 score $\geq 10 \%$ for primary cardiovascular disease prevention, regardless of cholesterol measurement, and in accordance with NICE guidance. Such interventions are likely to reduce the number of cardiovascular events in the following 10 years and potentially improve overall survival in this population.

\section{Conclusion}

As well as underpinning its aetiology, obesity adversely impacts the diagnosis, management and survivorship of women with endometrial cancer. Abnormal bleeding in morbidly obese premenopausal women should be taken seriously as a 'red flag' symptom for cancer and investigated appropriately. The management of obese women with endometrial cancer should include optimizing co-morbidities, multi-disciplinary team input and use of minimal access surgery, wherever possible, to provide the best care. Alternative evidence-based treatments for endometrial cancer are urgently needed for premenopausal women and those medically unfit for surgery. Weight loss should be encouraged to reduce the risk of endometrial cancer in the prevention setting, and to improve overall and cardiovascular-specific survival in the post-treatment setting. Whether weight loss also offers opportunities for the treatment of obese endometrial cancer patients is an exciting but unexplored area of research. 


\section{$\underline{\text { References }}$}

1. Cancer Research UK. Uterine cancer statistics 2018 [Available from:

http://www.cancerresearchuk.org/health-professional/cancer-statistics/statistics-by-cancertype/uterine-cancer\#heading-Zero.

2. Crosbie E, Morrison J. The emerging epidemic of endometrial cancer: Time to take action. The Cochrane database of systematic reviews. 2014(12):ED000095.

3. Rahib L, Smith BD, Aizenberg R, Rosenzweig AB, Fleshman JM, Matrisian LM. Projecting cancer incidence and deaths to 2030: the unexpected burden of thyroid, liver, and pancreas cancers in the United States. Cancer research. 2014;74(11):2913-21.

4. Renehan AG, Tyson M, Egger M, Heller RF, Zwahlen M. Body-mass index and incidence of cancer: a systematic review and meta-analysis of prospective observational studies. Lancet. 2008;371(9612):569-78.

5. Crosbie EJ, Zwahlen M, Kitchener HC, Egger M, Renehan AG. Body mass index, hormone replacement therapy, and endometrial cancer risk: a meta-analysis. Cancer epidemiology, biomarkers \& prevention : a publication of the American Association for Cancer Research, cosponsored by the American Society of Preventive Oncology. 2010;19(12):3119-30.

6. Bhaskaran K, Douglas I, Forbes H, dos-Santos-Silva I, Leon DA, Smeeth L. Body-mass index and risk of 22 specific cancers: a population-based cohort study of 5.24 million UK adults. Lancet. 2014;384(9945):755-65.

7. Moore SC, Lee I-M, Weiderpass E, Campbell PT, Sampson JN, Kitahara CM, et al. Association of leisure-time physical activity with risk of 26 types of cancer in 1.44 million adults. JAMA Intern Med. 2016;176(6):816-25

8. Calle EE, Kaaks R. Overweight, obesity and cancer: epidemiological evidence and proposed mechanisms. Nature reviews Cancer. 2004;4(8):579-91.

9. Kaaks R, Lukanova A, Kurzer MS. Obesity, endogenous hormones, and endometrial cancer risk: a synthetic review. Cancer epidemiology, biomarkers \& prevention : a publication of the American Association for Cancer Research, cosponsored by the American Society of Preventive Oncology. 2002;11(12):1531-43.

10. Renehan AG, Frystyk J, Flyvbjerg A. Obesity and cancer risk: the role of the insulin-IGF axis. Trends in endocrinology and metabolism: TEM. 2006;17(8):328-36.

11. Nagamani M, Stuart CA. Specific binding and growth-promoting activity of insulin in endometrial cancer cells in culture. American journal of obstetrics and gynecology. 1998;179(1):612.

12. Ye J, Keller JN. Regulation of energy metabolism by inflammation: a feedback response in obesity and calorie restriction. Aging. 2010;2(6):361-8.

13. Modugno F, Ness RB, Chen C, Weiss NS. Inflammation and endometrial cancer: a hypothesis. Cancer epidemiology, biomarkers \& prevention : a publication of the American Association for Cancer Research, cosponsored by the American Society of Preventive Oncology. 2005;14(12):2840-7. 14. Dossus L, Rinaldi S, Becker S, Lukanova A, Tjonneland A, Olsen A, et al. Obesity, inflammatory markers, and endometrial cancer risk: a prospective case-control study. Endocrine-related cancer. 2010;17(4):1007-19.

15. Mackintosh ML, Crosbie EJ. Obesity-driven endometrial cancer: is weight loss the answer? BJOG : an international journal of obstetrics and gynaecology. 2013;120(7):791-4.

16. Campbell KL, Foster-Schubert KE, Alfano CM, Wang CC, Wang CY, Duggan CR, et al. Reducedcalorie dietary weight loss, exercise, and sex hormones in postmenopausal women: randomized controlled trial. Journal of clinical oncology : official journal of the American Society of Clinical Oncology. 2012;30(19):2314-26.

17. Parker ED, Folsom AR. Intentional weight loss and incidence of obesity-related cancers: the lowa Women's Health Study. International journal of obesity and related metabolic disorders : journal of the International Association for the Study of Obesity. 2003;27(12):1447-52. 
18. Friedenreich CM, Neilson HK, Lynch BM. State of the epidemiological evidence on physical activity and cancer prevention. European journal of cancer. 2010;46(14):2593-604.

19. Schmid D, Behrens G, Keimling M, Jochem C, Ricci C, Leitzmann M. A systematic review and meta-analysis of physical activity and endometrial cancer risk. European journal of epidemiology. 2015;30(5):397-412.

20. Sjostrom L, Gummesson A, Sjostrom CD, Narbro K, Peltonen M, Wedel H, et al. Effects of bariatric surgery on cancer incidence in obese patients in Sweden (Swedish Obese Subjects Study): a prospective, controlled intervention trial. The Lancet Oncology. 2009;10(7):653-62.

21. Ward KK, Roncancio AM, Shah NR, Davis MA, Saenz CC, McHale MT, et al. Bariatric surgery decreases the risk of uterine malignancy. Gynecologic oncology. 2014;133(1):63-6.

22. MacKintosh ML, Derbyshire AE, McVey RJ, Bolton J, Nickkho-Amiry M, Higgins CL, et al. The impact of obesity and bariatric surgery on circulating and tissue biomarkers of endometrial cancer risk. Int J Cancer. 2018.

23. Soini T, Hurskainen R, Grenman S, Maenpaa J, Paavonen J, Pukkala E. Cancer risk in women using the levonorgestrel-releasing intrauterine system in Finland. Obstetrics and gynecology. 2014;124(2 Pt 1):292-9.

24. Iversen L, Sivasubramaniam S, Lee AJ, Fielding S, Hannaford PC. Lifetime cancer risk and combined oral contraceptives: the Royal College of General Practitioners' Oral Contraception Study. American journal of obstetrics and gynecology. 2017;216(6):580 e1- e9.

25. FSRH UK MEC. UK Medical Eligibility Criteria for Contraceptive Use 2016 [Available from: https://www.fsrh.org/standards-and-guidance/external/ukmec-2016-digital-version/.

26. Kitson SJ, Evans DG, Crosbie EJ. Identifying High-Risk Women for Endometrial Cancer Prevention Strategies: Proposal of an Endometrial Cancer Risk Prediction Model. Cancer prevention research. 2017;10(1):1-13.

27. Wise MR, Gill P, Lensen S, Thompson JM, Farquhar CM. Body mass index trumps age in decision for endometrial biopsy: cohort study of symptomatic premenopausal women. American journal of obstetrics and gynecology. 2016;215(5):598 e1- e8.

28. Funston G, O'Flynn H, Ryan NAJ, Hamilton W, Crosbie EJ. Recognizing Gynecological Cancer in Primary Care: Risk Factors, Red Flags, and Referrals. Adv Ther. 2018;35(4):577-89.

29. Wakefield Clinical Commissioning Group. Guidelines for GP Referral for Adult Routine MRI 2015 [Available from:

https://www.wakefieldccg.nhs.uk/fileadmin/site setup/contentUploads/Guidelines for GP Referra I for Adult Routine MRI v0.9.pdf.

30. Sundar S, Balega J, Crosbie E, Drake A, Edmondson R, Fotopoulou C, et al. BGCS uterine cancer guidelines: Recommendations for practice. European journal of obstetrics, gynecology, and reproductive biology. 2017;213:71-97.

31. Chung F, Yegneswaran B, Liao P, Chung SA, Vairavanathan S, Islam S, et al. STOP questionnaire: a tool to screen patients for obstructive sleep apnea. Anesthesiology. 2008;108(5):812-21.

32. Galaal K, Bryant A, Fisher AD, Al-Khaduri M, Kew F, Lopes AD. Laparoscopy versus laparotomy for the management of early stage endometrial cancer. The Cochrane database of systematic reviews. 2012;9:CD006655.

33. Walker JL, Piedmonte MR, Spirtos NM, Eisenkop SM, Schlaerth JB, Mannel RS, et al. Recurrence and survival after random assignment to laparoscopy versus laparotomy for comprehensive surgical staging of uterine cancer: Gynecologic Oncology Group LAP2 Study. Journal of clinical oncology : official journal of the American Society of Clinical Oncology. 2012;30(7):695700.

34. Janda M, Gebski V, Davies LC, Forder P, Brand A, Hogg R, et al. Effect of total laparoscopic hysterectomy vs total abdominal hysterectomy on disease-free survival among women with stage I endometrial cancer: a randomised clinical trial. JAMA. 2017;317(12):1224-1233. 
35. Wright JD, Burke WM, Wilde ET, Lewin SN, Charles AS, Kim JH, et al. Comparative effectiveness of robotic versus laparoscopic hysterectomy for endometrial cancer. Journal of clinical oncology : official journal of the American Society of Clinical Oncology. 2012;30(8):783-91.

36. Ind T, Laios A, Hacking M, Nobbenhuis M. A comparison of operative outcomes between standard and robotic laparoscopic surgery for endometrial cancer: a systematic review and metaanalysis. Int J Med Robotics Comput Assist Surg. 2017;13:e1851.

37. Matsuo K, Jung CE, Hom MS, Gualtieri MR, Randazzo SC, Kanao H, et al. Predictive Factor of Conversion to Laparotomy in Minimally Invasive Surgical Staging for Endometrial Cancer. International journal of gynecological cancer : official journal of the International Gynecological Cancer Society. 2016;26(2):290-300.

38. Corrado G, Vizza E, Cela V, Mere L, Bogliolo S, Legge F, et al. Laparoscopic versus robotic hysterectomy in obese and extremely obese patients with endometrial cancer: a multi-institutional analysis. Our J Sure Oncol. 2018; Sep 15. pii: S0748-7983(18)31296-4.

39. Gehrig PA, Cantrell LA, Shafer A, Abaid LN, Mendivil A, Boggess JF. What is the optimal minimally invasive surgical procedure for endometrial cancer staging in the obese and morbidly obese woman? Gynecologic oncology. 2008;111(1):41-5.

40. Uccella S, Bonzini M, Palomba S, Fanfani F, Ceccaroni M, Seracchioli R, et al. Impact of obesity on surgical treatment for endometrial cancer: a multicenter study comparing laparoscopy vs open surgery, with propensity-matched analysis. Journal of Minimally Invasive Gynecology. 2016;23:53-61.

41. Crosbie EJ, Estabragh ZR, Murphy J, Ahmed AS, Slade RJ. Apronectomy combined with laparotomy for morbidly obese endometrial cancer patients. Surgical oncology. 2011;20(4):e187-93. 42. Nout RA, van de Poll-Franse LV, Lybeert ML, Warlam-Rodenhuis CC, Jobsen JJ, Mens JW, et al. Long-term outcome and quality of life of patients with endometrial carcinoma treated with or without pelvic radiotherapy in the post operative radiation therapy in endometrial carcinoma 1 (PORTEC-1) trial. Journal of clinical oncology : official journal of the American Society of Clinical Oncology. 2011;29(13):1692-700.

43. Nout RA, Smit VT, Putter H, Jurgenliemk-Schulz IM, Jobsen JJ, Lutgens LC, et al. Vaginal brachytherapy versus pelvic external beam radiotherapy for patients with endometrial cancer of high-intermediate risk (PORTEC-2): an open-label, non-inferiority, randomised trial. Lancet. 2010;375(9717):816-23.

44. Lin LL, Hertan L, Rengan R, Teo BK. Effect of body mass index on magnitude of setup errors in patients treated with adjuvant radiotherapy for endometrial cancer with daily image guidance. International journal of radiation oncology, biology, physics. 2012;83(2):670-5.

45. Podzielinski I, Randall ME, Breheny PJ, Escobar PF, Cohn DE, Quick AM, et al. Primary radiation therapy for medically inoperable patients with clinical stage I and II endometrial carcinoma. Gynecologic oncology. 2012;124(1):36-41.

46. Van Der Steen-Banasik E, Christiaens M, Shash E, Coens C, Casado A, Herrera FG, et al. Systematic review: radiation therapy alone in medical non-operable endometrial carcinoma. European Journal of Cancer. 2016;65:172e181.

47. Van der Steen-Banasik E. Primary brachytherapy as a radical treatment for endometrial carcinoma. J Contemp Brachytherapy 2014;6:106e12.

48. de Boer SM, Powell ME, Mileshkin L, Katsaros D, Bessette P, Haie-Meder C, et al. Adjuvant chemoradiotherapy versus radiotherapy alone for women with high-risk endometrial cancer (PORTEC-3): final results of an international, open-label, multicentre, randomised, phase 3 trial. The Lancet Oncology. 2018;19(3):295-309.

49. Nagao S, Fujiwara K, Imafuku N, Kagawa R, Kozuka Y, Oda T, et al. Difference of carboplatin clearance estimated by the Cockroft-Gault, Jelliffe, Modified-Jelliffe, Wright or Chatelut formula. Gynecologic oncology. 2005;99(2):327-33.

50. Horowitz NS, Wright AA. Impact of obesity on chemotherapy management and outcomes in women with gynecologic malignancies. Gynecologic oncology. 2015;138(1):201-6. 
51. Gunderson CC, Fader AN, Carson KA, Bristow RE. Oncologic and reproductive outcomes with progestin therapy in women with endometrial hyperplasia and grade 1 adenocarcinoma: a systematic review. Gynecologic oncology. 2012;125(2):477-82.

52. Wan $\mathrm{YL}$, Holland $\mathrm{C}$. The efficacy of levonorgestrel intrauterine systems for endometrial protection: a systematic review. Climacteric : the journal of the International Menopause Society. 2011;14(6):622-32.

53. Walsh C, Holschneider C, Hang Y, Tieu K, Karlan B, Cass I. Coexisting ovarian malignancy in young women with endometrial cancer. Obstet Gynecol. 2005;106(4):693-9.

54. Kesterson JP, Fanning J. Fertility-sparing treatment of endometrial cancer: options, outcomes and pitfalls. J Gynecol Oncol. 2017;23(2): 120-24.

55. Falcone F, Laurelli G, Losito S, Di Napoli M, Granata V, Greggi S. Fertility preserving treatment with hysteroscopic resection followed by progestin therapy in young women with early endometrial cancer. J Gynecol Oncol. 2017;28(1):e2.

56. Hawkes AL, Quinn M, Gebski V, Armes J, Brennan D, Janda M, et al. Improving treatment for obese women with early stage cancer of the uterus: rationale and design of the levonorgestrel intrauterine device +/- metformin +/- weight loss in endometrial cancer (feMME) trial. Contemporary clinical trials. 2014;39(1):14-21.

57. Derbyshire AE, Ryan N, Crosbie EJ. Biomarkers needed to predict progestin response in endometrial cancer. BJOG : an international journal of obstetrics and gynaecology. 2017;124(10):1584.

58. Nagle CM, Crosbie EJ, Brand A, Obermair A, Oehler MK, Quinn M, et al. The association between diabetes, comorbidities, body mass index and all-cause and cause-specific mortality among women with endometrial cancer. Gynecologic oncology. 2018;150(1):99-105.

59. Secord AA, Hasselblad V, Von Gruenigen VE, Gehrig PA, Modesitt SC, Bae-Jump V, et al. Body mass index and mortality in endometrial cancer: A systematic review and meta-analysis. Gynecologic oncology. 2016;140(1):184-90.

60. Crosbie EJ, Roberts C, Qian W, Swart AM, Kitchener HC, Renehan AG. Body mass index does not influence post-treatment survival in early stage endometrial cancer: results from the MRC ASTEC trial. European journal of cancer. 2012;48(6):853-64.

61. Rock CL, Pande C, Flatt SW, Ying C, Pakiz B, Parker BA, et al. Favorable changes in serum estrogens and other biologic factors after weight loss in breast cancer survivors who are overweight or obese. Clinical breast cancer. 2013;13(3):188-95.

62. Irwin ML, Fabian C, McTiernan A. Risk Reduction from Weight Management and Physical Activity Interventions. Advances in experimental medicine and biology. 2015;862:193-212.

63. Kitson S, Ryan N, MacKintosh ML, Edmondson R, Duffy JM, Crosbie EJ. Interventions for weight reduction in obesity to improve survival in women with endometrial cancer. The Cochrane database of systematic reviews. 2018;2:CD012513.

64. Humpel N, Magee $\mathrm{C}$, Jones SC. The impact of a cancer diagnosis on the health behaviors of cancer survivors and their family and friends. Support Care Cancer. 2007;15(6):621-30.

65. Clark LH, Ko EM, Kernodle A, Harris A, Moore DT, Gehrig PA, et al. Endometrial Cancer Survivors' Perceptions of Provider Obesity Counseling and Attempted Behavior Change: Are We Seizing the Moment? Int J Gynecol Cancer. 2016;26(2):318-24.

66. Jernigan AM, Maurer KA, Cooper K, Schauer PR, Rose PG, Michener CM. Referring survivors of endometrial cancer and complex atypical hyperplasia to bariatric specialists: a prospective cohort study. Am J Obstet Gynecol. 2015;213(3):350 e1-10.

67. Felix AS, Bower JK, Pfeiffer RM, Raman SV, Cohn DE, Sherman ME. High cardiovascular disease mortality after endometrial cancer diagnosis: Results from the Surveillance, Epidemiology, and End Results (SEER) Database. Int J Cancer. 2017;140(3):555-64.

68. Ward KK, Shah NR, Saenz CC, McHale MT, Alvarez EA, Plaxe SC. Cardiovascular disease is the leading cause of death among endometrial cancer patients. Gynecologic oncology. 2012;126(2):1769. 
69. Kitson SJ, Lindsay J, Sivalingam VN, Lunt M, Ryan NAJ, Edmondson RJ, et al. The unrecognized burden of cardiovascular risk factors in women newly diagnosed with endometrial cancer: A prospective case control study. Gynecologic oncology. 2018;148(1):154-60.

70. Kitson SJ LJ, Sivalingam VN, Rutter MK, Crosbie EJ,. High prevalence of metabolic syndrome in women newly diagnosed with endometrial cancer. Gynecologic Oncology Reports (in press). 2018. 


\section{Figure legends}

Figure 1. Endometrial cancer incidence and mortality rates in the UK. The incidence of endometrial cancer has risen by over $50 \%$ in the last 20 years. Whilst this has resulted in an increase in the disease specific mortality rate, the widening gap between the number of cases diagnosed and deaths from the disease likely reflects the preponderance of good prognosis tumours associated with obesity.

Figure 2. Mechanisms through which obesity drives endometrial carcinogenesis. Excess adipose tissue is responsible for the creation of a state of oestrogen excess, hyperinsulinaemia and inflammation, which work in concert to upregulate gene transcription, cell proliferation and the accumulation of cancer-causing mutations within the endometrial cell. Abbreviations: $17 \beta H S D$ 17 $\beta$ hydroxysteroid dehydrogenase, ER oestrogen receptor, IKK IkB kinase, CXCR chemokine receptor, IL-6R interleukin-6 receptor, IR insulin receptor.

Figure 3. The levonorgestrel-releasing intrauterine system (LNG-IUS, Mirena) releases 20 micrograms of levonorgestrel per day directly into the uterine cavity, ensuring the highest level of the drug is delivered to the endometrial abnormality whilst minimising systemic side effects.

Figure 4. Photomicrographs of intra-uterine progestin-treated endometrial cancer showing a) residual endometrial neoplasia despite progestin treatment; and b) minor cytological atypia only with marked progestin effect.

Figure 5: Intra-uterine progestin plus sleeve gastrectomy for grade 1, stage 1a endometrial cancer with no myometrial invasion. Mary (who consents to her photo being shown) a) at baseline, weight $170 \mathrm{~kg}$; b) at 12 months, weight $120 \mathrm{~kg}$; c) MRI pelvis at baseline, showing bulky stage 1a EC (arrow); d) MRI pelvis at 12 months, showing complete radiological resolution (arrow), with complete endometrial response confirmed on biopsy. 
Table 1. STOP-BANG questionnaire screening for obstructive sleep apnoea. Individuals answering yes to $\geq 3$ questions are considered at high risk of the condition.

\begin{tabular}{ll}
\hline STOP & \\
\hline S (snore) & Loud snoring \\
$\mathbf{T}$ (tired) & Daytime tiredness \\
$\mathbf{O}$ (observed) & $\begin{array}{l}\text { Anyone observed cessation of breathing during } \\
\text { sleep }\end{array}$ \\
$\mathbf{P}$ (blood pressure) & Have or being treated for high blood pressure \\
\hline BANG & \\
\hline B (body mass index) & BMI $>35 \mathrm{~kg} / \mathrm{m}^{2}$ \\
$\mathbf{A}$ (age) & Age $>50$ years \\
$\mathbf{N}$ (neck) & Neck circumference $>40 \mathrm{~cm}$ \\
$\mathbf{G}$ (gender) & Male \\
\hline
\end{tabular}




\section{1}

2

3

4

5

6

7

8

9

10

11

12

13

14

15

16

17

18

19

20

21

22

23

24

25

26

27

28

29

30

31

32

33

34

35

36

37

38

39

40

41

42

43

44

45

46

47

48

49

50

51

52

53

54

55

56

57

58

59

60

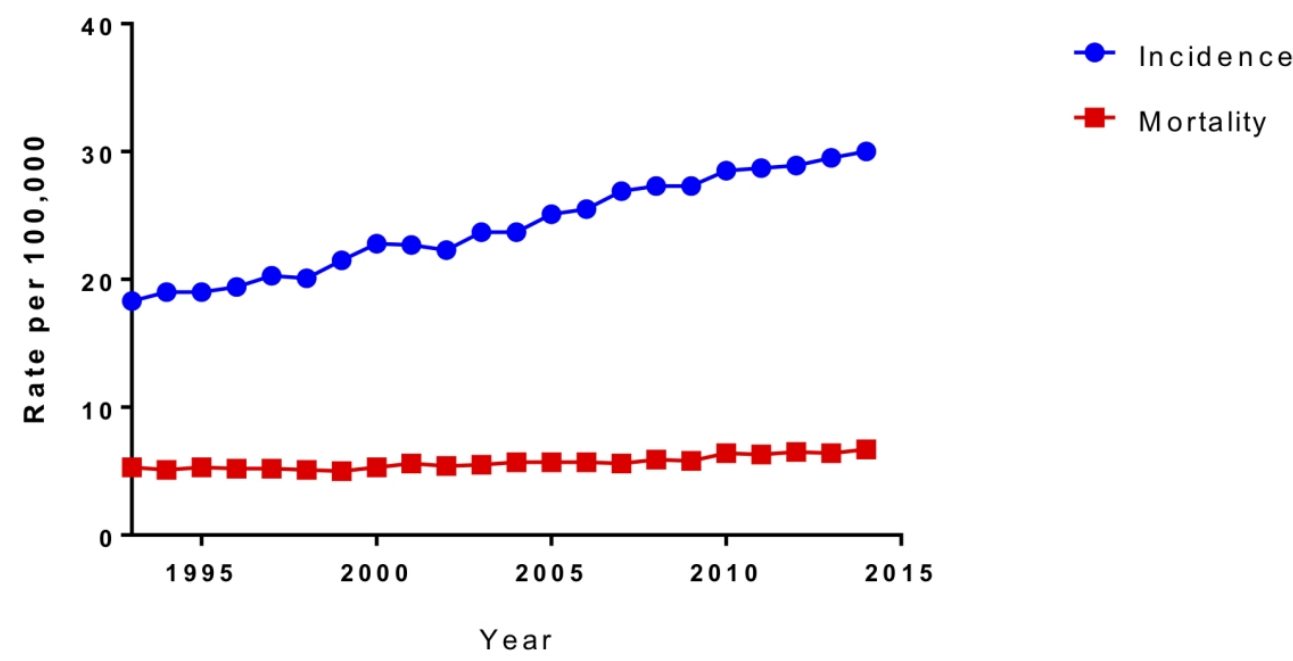

Figure 1. Endometrial cancer incidence and mortality rates in the UK. The incidence of endometrial cancer has risen by over $50 \%$ in the last 20 years. Whilst this has resulted in an increase in the disease specific mortality rate, the widening gap between the number of cases diagnosed and deaths from the disease likely reflects the preponderance of good prognosis tumours associated with obesity.

$154 \times 81 \mathrm{~mm}(300 \times 300$ DPI $)$ 


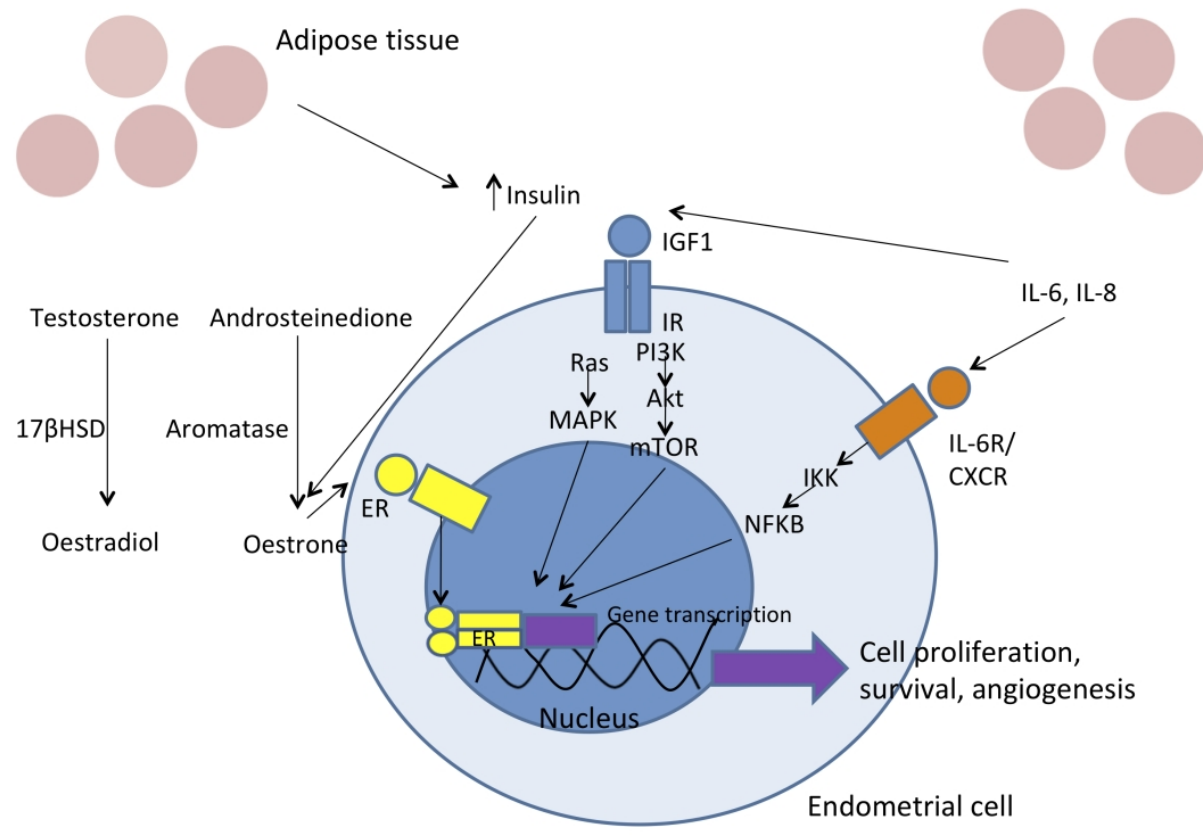

Figure 2. Mechanisms through which obesity drives endometrial carcinogenesis. Excess adipose tissue is responsible for the creation of a state of oestrogen excess, hyperinsulinaemia and inflammation, which work in concert to upregulate gene transcription, cell proliferation and the accumulation of cancer-causing mutations within the endometrial cell. Abbreviations: 17ßHSD 17 $\beta$-hydroxysteroid dehydrogenase, ER oestrogen receptor, IKK IkB kinase, CXCR chemokine receptor, IL-6R interleukin- 6 receptor, IR insulin receptor. 


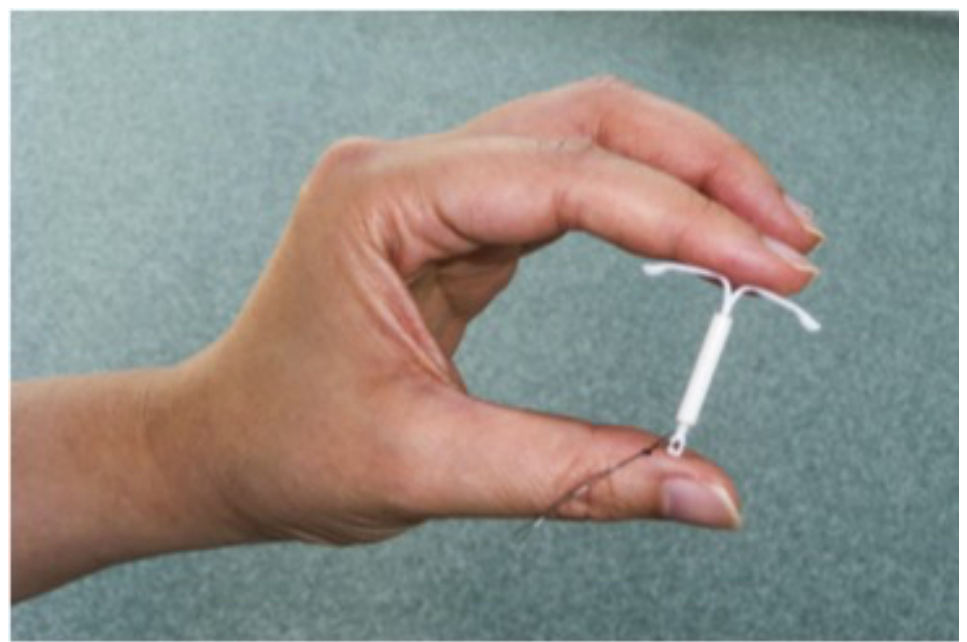

Figure 3. The levonorgestrel-releasing intrauterine system (LNG-IUS, Mirena) releases 20 micrograms of levonorgestrel per day directly into the uterine cavity, ensuring the highest level of the drug is delivered to the endometrial abnormality whilst minimising systemic side effects.

\section{$128 \times 86 \mathrm{~mm}(72 \times 72 \mathrm{DPI})$}



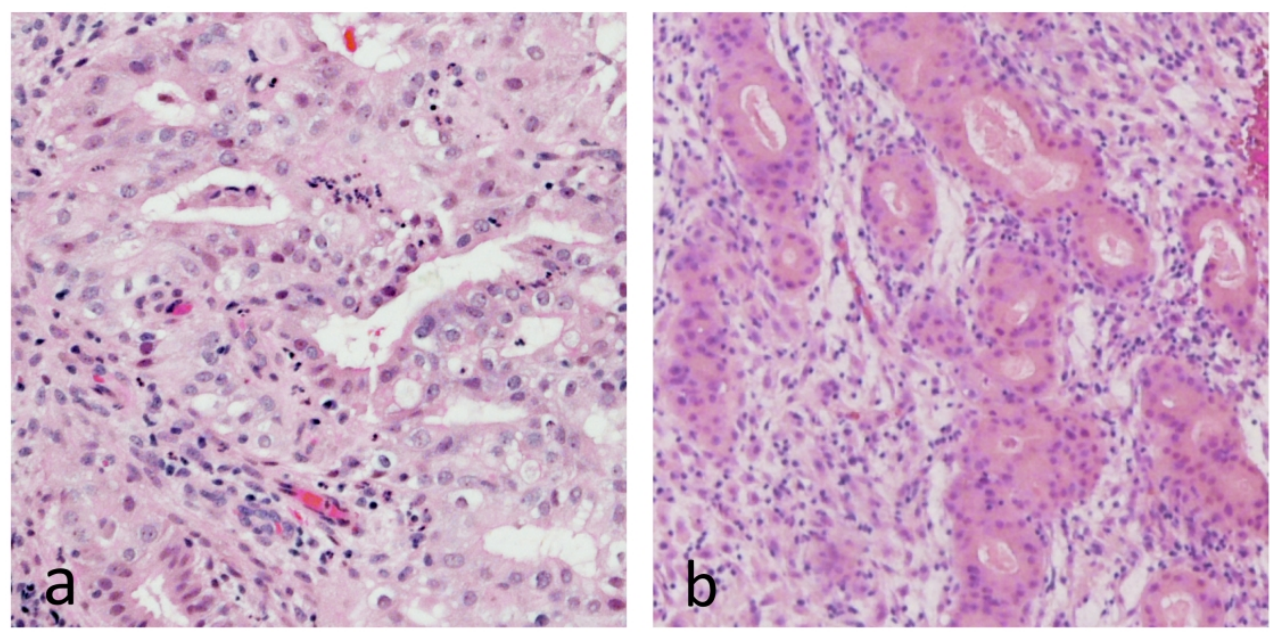

Figure 4. Photomicrographs of intra-uterine progestin-treated endometrial cancer showing a) residual endometrial neoplasia despite progestin treatment; and b) minor cytological atypia only with marked progestin effect.

$241 \times 121 \mathrm{~mm}(300 \times 300$ DPI $)$ 

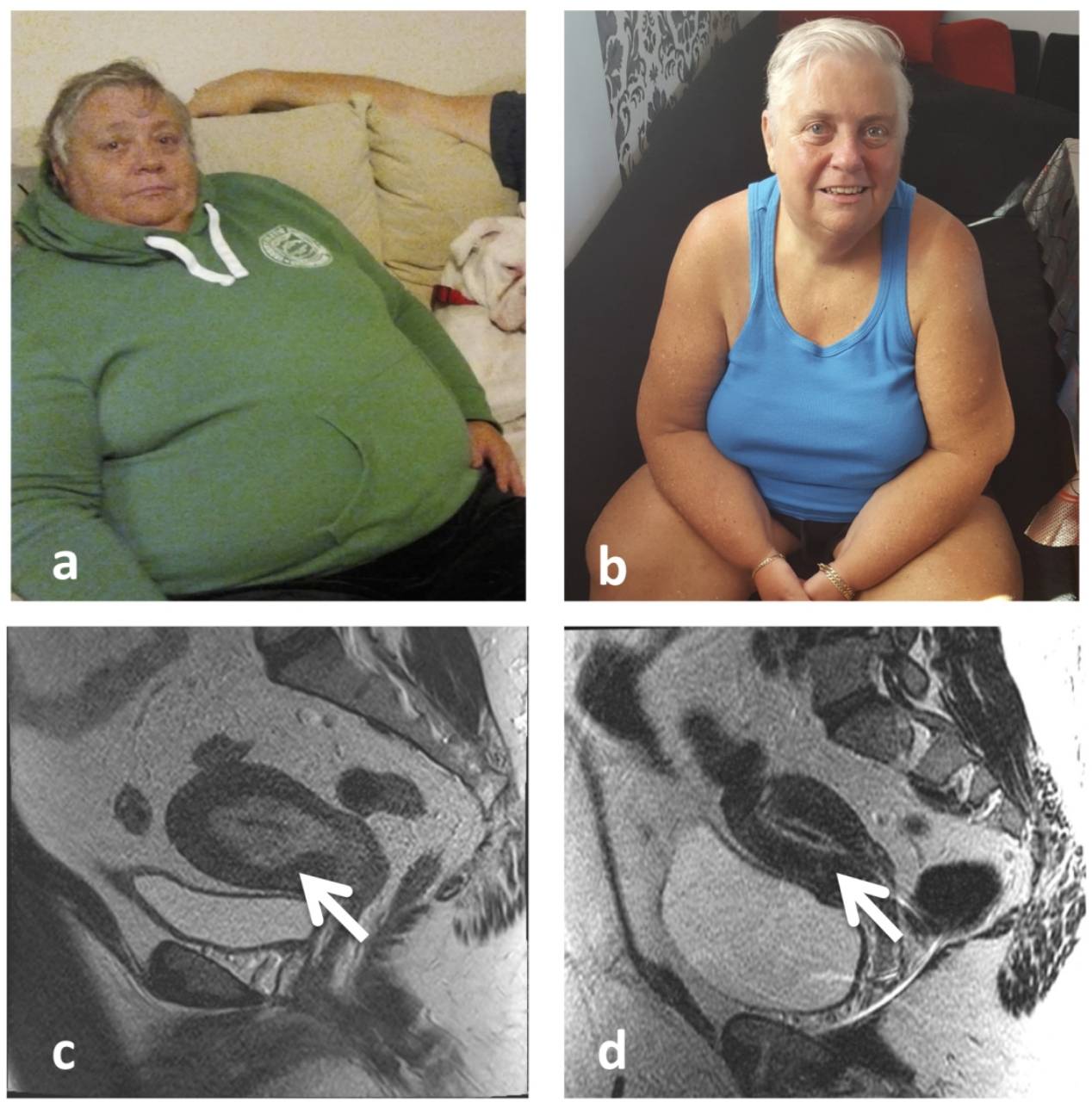

Figure 5: Intra-uterine progestin plus sleeve gastrectomy for grade 1, stage 1a endometrial cancer with no myometrial invasion. Mary (who consents to her photo being shown) a) at baseline, weight $170 \mathrm{~kg}$; b) at 12 months, weight $120 \mathrm{~kg}$; c) MRI pelvis at baseline, showing bulky stage 1a EC (arrow); d) MRI pelvis at 12 months, showing complete radiological resolution (arrow), with complete endometrial response confirmed on biopsy.

$134 \times 133 \mathrm{~mm}(300 \times 300 \mathrm{DPI})$ 


\section{CPD questions}

\section{Regarding endometrial cancer,}

1. Around 9,000 women die from the disease every year in the UK $\mathbf{F}$

2. Risk increases by $60 \%$ for every $5 \mathrm{~kg} / \mathrm{m}^{2}$ increase in body mass index $\mathbf{T}$

3. Lifetime risk is $25 \%$ for a woman with a $\mathrm{BMI}>40 \mathrm{~kg} / \mathrm{m}^{2} \mathbf{F}$

\section{Obesity drives endometrial carcinogenesis through}

4. The conversion of androgens to oestrogen by excess adipose tissue $\mathbf{T}$

5. Insulin resistance and chronic hyperinsulinaemia $\mathbf{T}$

6. The secretion of anti-inflammatory cytokines by activated adipocytes and macrophages $\mathbf{F}$

\section{The following have been shown to reduce endometrial cancer risk}

7. Physical activity $\mathbf{T}$

8. Bariatric surgery $T$

9. Levonorgesterol releasing intrauterine system $\mathbf{T}$

10. Oestrogen only HRT F

\section{Endometrial cancer,}

11. Is a common cause of abnormal bleeding in women $<50$ years of age $\mathbf{F}$

12. Is more likely in women with a history of polycystic ovary syndrome $\mathbf{T}$

\section{With regards to the primary treatment of endometrial cancer,}

13. Total hysterectomy with conservation of the ovaries should be performed $\mathbf{F}$

14. Total laparoscopic hysterectomy is associated with increased recurrence risk compared with open hysterectomy $\mathbf{F}$

15. Laparoscopy has proven superiority to robotic surgery in obese women $\mathbf{F}$

16. Radiotherapy is associated with recurrence rate of up to $18 \% \mathrm{~T}$

17. Intrauterine progestins have similar efficacy to oral progestins but fewer systemic side effects T

18. Medroxyprogesterone acetate $40 \mathrm{mg}$ daily is the effective dose $\mathbf{F}$

19. Relapse occurs in up to $25 \%$ of women following discontinuation of progestin treatment $\mathbf{T}$

With regards to adjuvant treatment in obese women with endometrial cancer,

20. Planning and delivering radiotherapy is easier $\mathbf{F}$

21. The risk of radiotherapy toxicity is greater due to the need for larger margins $\mathbf{T}$

22. Chemotherapy is associated with improved survival in women with early stage disease $\mathbf{F}$

\section{Survival following endometrial cancer in obese women is,}

23. Lower than for non-obese women $\mathbf{T}$

24. Adversely affected by an increased risk of death from cardiovascular disease $\mathbf{T}$ 
25. An opportunity to undertake cardiovascular risk assessment and to address modifiable risk factors $T$ 


\section{Referee(s)' Comments to Author}

\section{Referee: 1}

Comment 1: The authors point out that treatment by primary radiotherapy is less effective than surgery but primary rxt is not discussed in the text to any extent but only adjuvant treatment . clearly this needs rectifying and a discussion about primary RCT needs to be included. I would suggest that the first paragraph about adjuvant RXT is irrelevant . if a patient is unfit for surgery, then primary RXT needs to be discussed more new imaging techniques and high dose RXT has better outcomes than older modalities of treatment

Response: We thank the reviewer for their comment. We respectfully disagree that a discussion about adjuvant radiotherapy is irrelevant. However, it is true that our coverage of primary radiotherapy for medically unfit women is very brief. Please note that we are not clinical oncologists with expertise in this area and feel more than a brief description would not be appropriate in such a niche, specialist field. Nonetheless, we have done our best to flesh this section out a bit.

Comment 2: I would suggest that all women treated by progestogens or primary RXT need a baseline MRI scan. I would suggest treating women with an IUS alone with a $>1 b$ cancer is unlikely to be effective, do the authors need to discuss this in both young women desiring to retain fertility or in post menpausal women

Response: Thank you for this comment. We have added a sentence about the importance of imaging before treatment with progestins and emphasised that cure is unlikely at >stage 1a disease.

Comment 3: I am under the impression that RCTS or cohort in post op weight loss have been done but have been difficult to recruit to or get patient compliance, does this need discussed more. how to the authors propose to improve compliance with weight loss programmes after surgery

Response: There haven't been any large RCTs in this area. Feasibility studies with short duration of follow up suggest that lifestyle changes could be effective at inducing weight loss but the evidence for long term compliance is lacking. We do not have a magic bullet! However, we have added a comment about the diagnosis of endometrial cancer being a 'teachable moment' that could facilitate change.

Comment 4: Is there any evidence that super obese women have better surgical out comes in cancer centres?

Response: Not that I'm aware of.

Comment 5: There is growing and substantial evidence that Robotic surgery has better perioperative outcomes compared to standard lap surgery with less conversions. Robotic surgery has been underplayed in this review A finish RCT. AMJOG 1996 of robotic versus lap surgery demonstrated significantly less conversions in robotic surgery. There a several cohort studies demonstrating that conversion rates after robotic surgery compared to lap surgery . 
Response: The systematic reviews would support this comment about fewer conversions and we have changed this statement and the references we use to support it. However, we would like to make the point that this article is specifically about obese women - and rather focused on morbidly obese/super obese women, and - in general - the studies upon which the robotic surgery systematic reviews are based have not included BMI>50, 60 or 70 . So we do remain somewhat uncertain as to the benefit of robotic versus straight stick laparoscopy in this group.

Comment 6: I am not sure if the section on chemotherapy is particularly relevant, the content is generic to high bmi wome, the majority of obese women have low grade endometroid disease and not type 2 cancers.

Response: Again, we respectfully disagree with the reviewer. Of course most high BMI women have low grade low stage disease but there is still a requirement for chemotherapy for many and so we have kept this section but made the reviewer's point.

Comment 7: some of the trials of progestogens in treating early endometrial cancer to preserve fertility suggested there is a high rate of adnexal pathology, should such women have a MRI scan to assess adnexal pathology and also establish the radiological extent of disease, and should there be a cut off of stage of disease for medical management

Response: Yes - we have addressed this at comment 2

Comment 8: is the prognosis of progestogen treatment of endometrial cancer different in pre-menopausall or menopausal women, what type and dose regimens do the authors recommend in the different age groups

Response: We do not know the answer to this question as the studies have not been done and there are no recommended regimens. We have added further wisdom from our own experience but it is not evidence based. We are happy to remove this if the Editorial team prefers.

Comment 9: I would be interested to know if the authors are aware if there are any differences in adequacy of lympadenectomy in super obese women compared to normal bmi women

Response: It would appear that lymphadenectomy is attempted less often in super obese women than it is in lean women

\section{Referee: 2}

Comment 1: $\mathrm{COC}$ in $\mathrm{BMI}>35$ is a UKMEC 3 . This guidance needs to be included when recommending $\mathrm{COC}$ for the obese population.

Response: Thanks, we have added this statement.

Comment 2: I disagree with the statement that the slowly increasing death rate of EC is due to an improvement in treatments. The death rate fell 10 years ago and is now rising again (https://www.cancerresearchuk.org/health-professional/cancer-statistics/statistics-bycancer-type/uterine-cancer/mortality\#heading-Two). Could it not be that this is due to the 
stage/age profile of the EC patients and that despite an increase in incidence the majority of the cases are early stage and so women are not going to die of their disease?

Response: Sure, that's a definite possibility. We have added this as a potential explanation for the rise in death rates.

Comment 3: You might want to mention that physical activity appears to be an independent risk factor for EC in addition to obesity.

Response: Yes, good idea - have added this statement.

Comment 4: I'm very surprised at the $125 \mathrm{~kg}$ weight limit for MRI scanners, I suspect this information may be quite out of date.

Response: Certainly modern MRI scanners have a much higher weight limit but unfortunately many hospitals in the UK do not have state-of-the-art - or even modern equipment. We have altered this sentence slightly to avoid any misunderstanding.

Comment 5: Trying to get morbidly obese women to perform an exercise stress test is often not technically feasible (due to mobility issues). Would it be better to say 'other tests to investigate cardiac function such as exercise stress test or cardiac MRI'.

Response: Yes, good point. We have changed this.

Comment 6: Why has Ind's meta-analysis of 36 studies on EC not be included when discussing the role of robotic surgery rather than a meta-analysis of hysterectomy for benign disease and old studies from single institutions? Ind's meta-analysis showed significantly lower conversions to laparotomy as well as shorter hospital stay, lower EBL and less overall complications.

Response: We have changed the supporting references for the statement about robotic surgery. We have included a statement that the conversion rate is lower with robotic surgery but made the point that most studies have not looked at super obese women. We have added a comment about lymphadenectomy for Reviewer 1.

Comment 7: A long veress needle - might want to comment that many gynae oncs use an open technique to avoid issues with Veress needles

Response: I think it varies from surgeon to surgeon. I have added this point though.

Comment 8: The performance of an apronectomy at the time of primary surgery is controversial due to the significantly increased postoperative morbidity. It is not a procedure that is widely performed with only a few retrospective single institution publications and supporting its usage. The paper by Crosbie also showed that a third of patients had increased their weight since surgery at 24 months, indicating that it is not a long-term sustained solution for many women. I would advise that the wording of the sentence be changed to 'Apronectomy at the time of hysterectomy has been reported although this is associated with significantly greater post op morbidity and the effect may not be sustained long-term'. 
Response: I disagree with this. If there is no evidence for its use then there is also no evidence for it causing more post op morbidity. I have recently reviewed a systematic review of apronectomy for endometrial cancer and I do not think the reviewer's comment is upheld by the data. However, there have been no RCTs and so I have taken out figure 3 (in case showing the success of the procedure should be reviewed as promotional) and down-played the language. The reviewer misses the point, though, because the point of apronectomy is not to achieve weight loss, it is to improve surgical access and safety in super obese women (BMI>60 or 70) in whom surgery is otherwise extremely challenging.

Comment 9: Where is the survival date in figure 1 from? It does not give an accurate picture of the pattern of mortality and EC (https://www.cancerresearchuk.org/healthprofessional/cancer-statistics/statistics-by-cancer-type/uterine-cancer/mortality\#headingTwo)

Response: That is because we have put incidence and mortality on the same figure - so the rise in death rates from 5 to 7 per 100,000 looks less dramatic on a scale that goes up to 40 than it does in a scale that goes up to 7. But it is re-drawn from CRUK Stats (same data), so it definitely shows the same thing.

Comment 10: Figure 3 needs to be removed. Apronectomy at the time of hysterectomy is a treatment that does not have trial evidence to support its usage in routine clinical practice and should not be promoted in this way.

Response: This figure has been removed at the reviewer's suggestion.

\section{Comment 11: Questions}

I disagree with the answer to question 7

Response: Sorry, this was a typo and has been changed. Thanks for spotting it.

What is the definition of 'rare'? The percentage of women under 50 diagnosed with EC is $>5 \%$ and but it depends on what cut off you are using for 'rare'. If you are going to ask this question it would be better to have a percentage rather than saying 'rare'.

Response: Fair enough, we have rephrased this question.

Comment 12: I disagree with the answer to 'Robotic surgery has proven superiority to laparoscopy in obese women' because there is meta-analysis evidence that it is superior in EC for complications, hospital stay, and conversion rate, and since this is a predominantly obese population then yes there is evidence, the only downside is that it's more expensive.

Response: Yes, this question has also been re-worded. 


\section{Abstract}

\section{Key content}

- Endometrial cancer has the strongest association with obesity of the 20 most common tumour types

- Endometrial cancer should be considered in young obese women with irregular and heavy menstrual bleeding

- Obese women should be encouraged to lose weight and to consider using the Mirena coil or combined oral contraceptive pill for contraception to reduce their risk of endometrial cancer

- Surgery for endometrial cancer should be performed using minimal access techniques, wherever possible, to reduce the risk of post-operative complications. Thorough preoperative assessment and experienced surgeons are essential.

- Alternative treatments for those unfit for or who decline surgery include oral or intrauterine progestins and radiotherapy, but have lower efficacy and are associated with a higher risk of disease relapse.

- Obesity is associated with a reduction in overall survival following endometrial cancer due to an increase in cardiovascular mortality and may also impact on disease specific survival.

- High quality, adequately powered randomised controlled trials are required to determine whether weight loss following primary endometrial cancer treatment improves survival.

\section{Learning objectives}

- To further understanding of the mechanisms through which obesity drives endometrial carcinogenesis

- To improve understanding of the potential difficulties associated with the management of endometrial cancer in obese women

- To increase knowledge of alternative treatment options for women unfit for or who decline standard endometrial cancer management

\section{Ethnical issues}

- How should the increasing numbers of younger, premenopausal women with endometrial cancer be managed?

- Should super obese women with endometrial cancer only be treated in cancer centres?

- How do you counsel a woman about her weight and cardiovascular disease risk after treating her endometrial cancer?

\section{Key words}

Endometrial cancer, obesity, weight loss, levonorgestrel-releasing intrauterine system (LNG-IUS), Mirena, minimally invasive surgery, cardiovascular disease risk 


\section{Introduction}

Endometrial cancer is the most common gynaecological cancer in the UK, with over 9000 new diagnoses made every year ${ }^{(1)}$. The incidence of endometrial cancer is rising year on year (figure 1) and this trend is set to continue both in the UK and globally ${ }^{(2)}$. As a consequence, endometrial cancer is expected to overtake lung and colorectal cancer to become the third most common cancer in US women by $2030^{(3)}$. Deaths from endometrial cancer are also climbing but at a slower rate (figure 1), reflecting improvements in treatment, most likely due to the preponderance of good prognosis tumours. This means that more women are now surviving endometrial cancer than ever before.

The rising incidence of endometrial cancer has been blamed on the obesity epidemic. Endometrial cancer ranks highest amongst all cancers in its association with obesity ${ }^{(4)}$. Every $5 \mathrm{~kg} / \mathrm{m}^{2}$ increase in body mass index (BMI) is linked to a $60 \%$ increase in endometrial cancer risk ${ }^{(5)}$, and this relationship is even stronger at an extreme BMI. A woman with a BMI $>40$ is nearly ten times more likely to be diagnosed with endometrial cancer than a normal weight woman, giving her a lifetime risk of disease of $10-15 \%$. Such is the strength of this association that $40 \%$ of endometrial cancer diagnoses are directly attributable to obesity and ultimately preventable ${ }^{(6)}$. Obesity is related to a sedentary lifestyle and low levels of physical activity, which are also independent risk factors for the disease $\mathrm{e}^{(7)}$. Obesity is most strongly linked with good prognosis type 1 (endometrioid) tumours, but its influence is also implicated in the pathogenesis of more biologically aggressive type 2 tumours ${ }^{(5)}$.

\section{Mechanisms through which obesity drives endometrial carcinogenesis}

There are three distinct, but inter-related, mechanisms through which obesity influences endometrial carcinogenesis: excess oestrogen exposure, insulin resistance and inflammation (figure 2).

Adipose tissue produces the enzymes aromatase and $17 \beta$-hydroxysteroid dehydrogenase (17 $\beta$-HSD), responsible for the conversion of the androgens androstenedione and testosterone to oestrogens oestrone and oestradiol, respectively ${ }^{(8)}$. Hyperinsulinaemia leads to a decrease in sex-hormone binding globulin (SHBG), which increases the bioavailable fraction of oestrogen. The net effect is excess oestrogen exposure without the natural counterbalance of cyclical progesterone in postmenopausal and anovulatory premenopausal women. Oestrogen drives endometrial proliferation whilst simultaneously inhibiting apoptosis. Oestrogen also promotes rapid cellular turnover through local production of insulin-like growth factor-1 (IGF-1) and, in so doing, increases the risk of accumulation of mutations in key proto-oncogenes and tumour suppressor genes ${ }^{(9)}$.

Obesity is associated with insulin resistance and chronic hyperinsulinaemia. There is now substantial in vitro evidence of a direct effect of insulin and IGF-1 on the endometrium, with activation of the insulin receptor promoting cellular proliferation and survival| ${ }^{(10,11)}$. These effects are mediated through the PI3K-Akt-mTOR and MAPK pathways. Hyperinsulinaemia also increases ovarian androgen production and its peripheral aromatisation to oestrogen.

Adipose tissue expansion and its subsequent hypoxia initiates the secretion of pro-inflammatory cytokines by activated adipocytes and infiltrating macrophages, creating an inflammatory environment ${ }^{(12)}$. Activation of the NFkB pathway by inflammatory cytokines inhibits apoptosis, 
overrides cell cycle arrest and causes the transcription of genes encoding pro-inflammatory cytokines, leading to a vicious inflammatory cycle and tumourigenesis ${ }^{(13)}$. Inflammation also promotes insulin resistance, and IL- 6 stimulates aromatase activity and the conversion of testosterone to oestrogen within adipose tissue ${ }^{(14)}$.

Knowledge of these key drivers of obesity-driven endometrial carcinogenesis can facilitate the development of targeted prevention and treatment strategies.

\section{Preventing obesity-driven endometrial cancer}

Tackling obesity is a logical first step to endometrial cancer prevention ${ }^{(15)}$. Women should be encouraged to attain and maintain a normal weight as key components of living a healthy lifestyle. Obese women who lose weight through dieting have been shown to lower their serum oestrone and testosterone levels, whilst increasing insulin sensitivity and SHBG levels ${ }^{(16)}$. Current evidence suggests that endometrial cancer risk is not reduced until weight loss of at least $20 \mathrm{lbs}$ is achieved, however (17).

There have been no trials of physical activity for the primary prevention of endometrial cancer, but exercise is likely to be an effective strategy through its beneficial effect on BMI. Women should be advised to undertake at least 20 minutes of moderate intensity exercise, sufficient to raise their heart rate, five times per week, similar to the recommendations for breast cancer prevention ${ }^{(18)}$. Regular physical activity reduces the risk of endometrial cancer by $20-30 \%$, with even greater benefits for those undertaking higher intensity exercise of longer duration ${ }^{(19)}$.

For morbidly obese women (i.e. those with a $\mathrm{BMI} \geq 40 \mathrm{~kg} / \mathrm{m}^{2}$ ), bariatric surgery is an effective means of reducing endometrial cancer risk, resulting in a $70-80 \%$ lower disease risk compared with BMImatched controls ${ }^{(20,21)}$. Whilst the greatest benefit is seen in women achieving a normal body mass following surgery, even those who remain obese have a lower risk of endometrial cancer, suggesting that the effect is predominately mediated through rapid improvements in insulin sensitivity ${ }^{(21,22)}$. Whilst cancer prevention is not currently listed as an indication for bariatric surgery by the National Institute of Health and Clinical Care Excellence (NICE), eligible women should be counselled about the additional positive effects of weight loss surgery on endometrial cancer risk.

Young obese women should be advised about contraceptive choices that reduce endometrial cancer risk. Use of the levonorgestrel-releasing intrauterine system (Mirena) is associated with a $54 \%$ reduction in endometrial cancer risk, which increases to $75 \%$ if treatment is prolonged ${ }^{(23)}$. Five years or more of exposure to the combined oral contraceptive pill is effective in reducing the risk of endometrial cancer by $50 \%$, with durable protection out to 30 years post-treatment ${ }^{(24)}$, although the risks may outweigh the benefits in obese women with multiple cardiovascular risk factors. Indeed, a $\mathrm{BMI}>35 \mathrm{~kg} / \mathrm{m}^{2}$ is a relative contraindication for the combined oral contraceptive pill (UKMEC 3$)^{(25)}$.

Well-designed primary endometrial cancer prevention trials are needed to provide robust evidence for risk reducing interventions, but these will be very expensive and time-consuming. Risk prediction models that refine the population most likely to benefit from targeted prevention strategies are needed to ensure trials are adequately powered and with sufficient follow up to generate clear answers (26).

\section{Diagnosing endometrial cancer in obese women}




\section{Treating obese women with endometrial cancer}

\section{Surgery}

Total hysterectomy and bilateral salpingo-oophorectomy is the primary treatment for most women with endometrial cancer and is curative for those with early stage disease (limited to the uterus)(30). Gynaecologists undertaking this procedure in obese women are faced with several potential difficulties, however, including the presence of co-morbidities, including cardiovascular disease and obstructive sleep apnoea (OSA), which reduce their fitness for anaesthesia; restricted surgical access due to intra-abdominal obesity; and an increased risk of post-operative complications, particularly wound infection, if open surgery is required.

In order to allow time for pre-surgical optimisation, a thorough pre-operative assessment should be performed soon after diagnosis of endometrial cancer. This should include at least an electrocardiogram (ECG), to assess arrhythmias, echocardiography (to determine left ventricular function and the presence of valvular abnormalities) and other tests to investigate cardiac function such as an exercise stress test or cardiac MRIpotentially an exercise stress test to look for significant eoronary artery disease. The STOP-BANG questionnaire is used to screen women for OSA, with formal diagnostic testing using polysomnography (sleep study including recordings of heart rate, brain and muscle activity and eye movements) for those identified as being at high risk with a score of 3 or more (table 1$)^{(31)}$. An anaesthetic review to ensure that the woman will be able to tolerate a Trendelenburg position and to assess the need for high dependency unit post-operative care is often required.

Surgery should ideally be performed through a minimal access technique, as this has been shown to be associated with a shorter hospital stay, lower infection rate and less post-operative pain ${ }^{(32,33)}$. 
Importantly, the meta-analysisavailable data showed no difference in survival or rates of recurrence between endometrial cancer patients undergoing a total laparoscopic hysterectomy compared with those treated by laparotomy ${ }^{(33,34)}$. Robotic surgery may have benefits over laparoscopy in obese women as data from a small retrospective study suggested thatbecause the operating time, blood loss, hospital stay and rate of conversion to laparotomy operative complication rate-iwas lower in the former group, although there were no differences in rate of conversion to laparotomy and-cost remains prohibitive for many hospital trusts ${ }^{(35-37)}$. Open surgery remains a substantial risk for morbidly obese women, particularly those with a $B M 1>50-60 \mathrm{~kg} / \mathrm{m}^{2}$, since conversion rates are much higher than for lean women ${ }^{(36)}$. There are currently insufficient data to inform the safest choice of surgical route in women with a BMI $>50-60 \mathrm{~kg} / \mathrm{m}^{2}$, in whom conversion rates are much higher than for lean women ${ }^{(38,39)}$.

Few studies have compared the yield of pelvic and para-aortic lymph nodes in obese endometrial cancer patients undergoing different modalities of surgery, although lymphadenectomy would appear to be less frequently attempted at extremely high BMIs, by any surgical route ${ }^{(39,40)}$. If open surgery is planned, consideration should-could be given to combining the procedure with an apronectomy, to remove the excess skin and fat hanging over the pubic area, to improve access (figure 3$)^{(41)}$. In rare instances where even this is not feasible, vaginal hysterectomy $+/$ - removal of the ovaries may be performed under regional anaesthesia in those with localised endometrioid endometrial cancer $(30)$.

The set-up in theatre is critical to reduce the risk of intra- and post-operative complications and requires good multidisciplinary working between surgical, anaesthetic and nursing team members. This includes ensuring that the operating table is able to accommodate the patient's weight; a hover mattress is used to transfer the patient to the operating table; a beanbag or shoulder supports are used to prevent the patient slipping down the table when in head-down tilt; an open entry technique or a long veress needle is used; an adequate number and length of ports are available to make operating as ergonomic as possible; and that experienced surgeons and assistants are available to undertake the procedure. A steep Trendelenburg position is required in order to move the bowel as far as possible out of the operative field and may be aided with the use of fan retractors. The Trendelenburg position may need to be reduced episodically to avoid respiratory compromise.

\section{Radiotherapy}

Adjuvant radiotherapy reduces the rate of pelvic recurrence in women with intermediate-high risk endometrial cancer ${ }^{(42)}$. It is preferentially administered as vaginal brachytherapy, where the risk of lymph node metastases is low, as this has been demonstrated to be non-inferior to external beam radiotherapy in achieving locoregional control but is associated with fewer bladder and gastrointestinal side effects( ${ }^{(43)}$. and those who are bleding heavily. Radiotherapy, hower, appears to be inferio tosurgery for

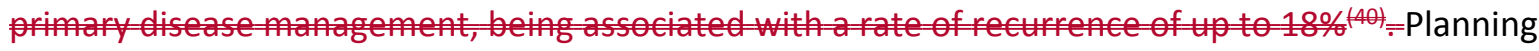
and delivering radiotherapy is more difficult in obese women due to greater daily shifts and larger errors, meaning that it is harder to accurately target the radiotherapy beam and avoid non-affected tissues ${ }^{(44)}$. Greater margins are, therefore, required to achieve optimal control. 
ItPrimary radiotherapy is an alternative option can also be used as definitive treatment infor women unfit for surgery and those who are bleeding heavily. Radiotherapy, however, Most published data suggest that primary radiotherapy is appears to be inferior to surgery for primary disease management, being associated with a rate of recurrence of up to $18 \%{ }^{(45)}$. Combined external beam radiotherapy and intracavitary brachytherapy is associated with best locoregional control and long term outcomes, however, high dose brachytherapy alone may prove sufficient in early stage low grade endometrial cancer ${ }^{(46)}$. The accurate placement of intrauterine applicators for the delivery of brachytherapy is limited by the patient's fitness for general anaesthesia and is technically challenging at extremely high BMIs. Some centres place their intrauterine applicators under sedation or with no anaesthesia ${ }^{(47)}$, but this approach is not widely practiced or available. There are no RCTs comparing surgery or hormone treatment and primary radiotherapy with curative intent in endometrial cancer.

\section{Chemotherapy}

The recently published PORTEC-3 study has provided necessary evidence on which to base decisions regarding the use of chemotherapy in endometrial cancer ${ }^{(48)}$. The trial demonstrated a benefit from combined chemo-radiotherapy, using platinum and paclitaxel chemotherapy, in terms of an improvement in failure-free survival only in women with stage III disease. Adjuvant chemotherapy had no impact on survival in women with high-risk disease confined to the uterus or on overall survival.

Most morbidly obese women present with low grade, early stage disease and do not require adjuvant chemotherapy. For obese women with intermediate-high risk disease, eEnsuring that obese women receive-an adequate dose of chemotherapy is challenging. The formulae used to estimate glomerular filtration rate and to dose carboplatin underestimate creatinine clearance in individuals with a large body surface area potentially resulting in the delivery of inadequate doses of the drug ${ }^{(49)}$. Obese women also have larger volumes of distribution, which can reduce target tissue drug levels, and can clear chemotherapeutics from the circulation at a different rate to leaner women, particularly if there is co-existing fatty liver disease or renal dysfunction(50). There are, however, no clinical trial data available to guide chemotherapy dosing in obese women. Dose capping is often employed to try to prevent toxicity but may compromise clinical outcome, including progression-free and overall survival.

\section{Conservative treatment}

For women with atypical hyperplasia and low grade endometrioid endometrial cancer with minimal myoinvasion, who are either medically unfit for surgery or who decline hysterectomy because of a desire to preserve fertility, the levonorgestrel-releasing intrauterine system (LNG-IUS, Mirena, figure 3) or oral progestins are alternative treatment options $(\underline{151})$. Initial success rates of $50 \%$ and $65 \%$ have been reported for stage 1a low grade endometrial cancer and atypical hyperplasia, respectively, but recurrence rates may be as high as $25 \%$. Intrauterine progestin may have equivalent clinical efficacy to oral progestins but fewer systemic side effects $(51,52)$. There have been no randomised controlled trials comparing these treatments to standard care, with the available data on their effectiveness derived from a small number of observational studies with only limited follow-up. 
Baseline imaging is important if conservative treatment is chosen. Progestin treatment is unlikely to be curative if there is $>$ Stage 1a disease, but it may stabilise disease progression and alleviate symptoms, with benefits for quality of life, if disease is more advanced. There is a high prevalence of coincident adnexal masses in women treated conservatively for endometrial cancer, and serial imaging may be necessary to exclude sinister pathology ${ }^{(53)}$. Expert review of the index biopsy and a repeat sample taken at the time of LNG-IUS insertion/oral progestin prescription is also important to rule out rapid progression and/or high grade disease.

The optimal dose and route of progestin therapy for the conservative management of atypical hyperplasia and endometrial cancer is not known. Medroxyprogesterone acetate (MPA) 200-400mg daily in single or split doses is commonly used but is associated with weight gain, headaches and an increased risk of venous thromboembolic events ${ }^{(54)}$. The LNG-IUS ensures compliance and, crucially, does not cause weight gain. It can be inserted in clinic in the majority of women, even those with extremely high BMIs $\left(>60-70 \mathrm{~kg} / \mathrm{m}^{2}\right)$, if a Winterton speculum and colposcopy chair are available. Around 20-30\% experience increased bleeding and pain in the first six weeks, but this is not of oncological consequence. Single agent LNG-IUS is probably sufficient if the endometrium is thickened but there is no intra-uterine mass. Resection of large intrauterine polyps prior to LNG-IUS insertion may improve response rates ${ }^{(55)}$ but large volume disease may benefit from combined treatment with both oral and intrauterine progestin, particularly if the first endometrial surveillance biopsy at 3 months does not show a marked progestin response (figure 4). There is no evidence that treatment schedules should differ according to menopausal status.

Using the 6-12 month progestin treatment window to address endometrial cancer risk factors, including obesity and insulin resistance, may improve outcomes for obese endometrial cancer patients. Weight loss may increase pathological complete response rates to progestin treatment ${ }^{(22)}$; reduce recurrence after treatment cessation; enable minimal access hysterectomy if progestin treatment fails; improve natural fecundity; enable assisted reproduction and/or improve the likelihood of its success; and improve general health and quality of life (figure 54 ). The ongoing ANZGOG feMME trial aims to be the first randomised controlled trial to determine the efficacy of treatment with the Mirena coilLNG-IUS \pm metformin \pm weight loss on pathological complete response rate in early stage endometrial cancer in obese women at six months ${ }^{(56)}$.

Follow-up of women using these alternative treatments should include an endometrial biopsy every 3 months in the first year and twice yearly thereafter to check for disease resolution, progression or recurrence. Interval MRI imaging is also recommended if surgery could be an option. Currently there are no validated biomarkers that predict treatment response ${ }^{(57)}$ and most experts opine that hysterectomy should be performed once childbearing is complete, irrespective of disease status, in those who choose to avoid hysterectomy for fertility-sparing reasons $(\underline{30})$.

\section{Long term outcomes in obese endometrial cancer patients}

Epidemiological studies have suggested that obesity adversely affects prognosis for endometrial cancer patients 58 , but it is unclear whether this is due to an increased risk of endometrial cancerspecific death or death from other causes ${ }^{(59)}$. Endometrial cancer management is frequently suboptimal in obese women, because of the difficulties described above. This, in itself, adversely affects survival. When obese women do receive standardised treatment consistent with non-obese 
women, as happened in the MRC ASTEC randomised controlled trial, there is no difference in endometrial cancer-specific survival between the two groups $(60)$.

Whether weight loss improves endometrial cancer-specific survival is currently unknown. Studies in breast cancer have shown that weight loss reduces markers of recurrence, including total and free oestradiol, insulin, adiponectin and inflammatory and cancer-promoting proteins ${ }^{(61,62)}$. Few studies have investigated the benefits of weight loss following treatment for endometrial cancer and all have had limited follow-up, have been underpowered to examine the effect of the intervention on survival and have used diet and exercise regimes that failed to achieve substantial weight loss (63). Only one RCT reported survival at 24 months, and found no improvement in overall survival with a lifestyle and behavioural intervention.

Achieving and maintaining clinically meaningful weight loss is extremely challenging; however, endometrial cancer may be the patient's first obesity 'symptom' and serve as an important 'teachable moment' underpinning their subsequent lifestyle choices ${ }^{(64)}$. Furthermore, the gynaecologist may be uniquely placed to deliver this teachable moment: one study found that all obese endometrial cancer survivors counselled by their gynaecological oncologist attempted weight loss, compared to just $56 \%$ counselled by their GP ${ }^{(65)}$. Successful weight loss was reported more frequently when the intervention was delivered within 6 months of endometrial cancer diagnosis $(65$, 66).

Besides any potential impact on disease specific survival, weight loss could improve overall survival in women with a history of endometrial cancer by reducing the risk of death from other causes. Cardiovascular disease remains the commonest cause of death in women with early stage endometrial cancer, with twice as many deaths occurring from myocardial infarction, stroke and heart failure than cancer $(67,68)$. This is due to an increased prevalence of obesity, hypertension, hypercholesterolaemia and diabetes in endometrial cancer survivors compared with the general population and these risk factors are more likely to be undiagnosed and inadequately managed $(\underline{69}, \underline{70})$. Following primary endometrial cancer treatment, women should have their blood pressure, cholesterol and $\mathrm{HbA1C}$ measured and their 10-year cardiovascular disease risk calculated using the online QRISK2 calculator (https://qrisk.org/). Cardiovascular risk factors should be optimised, including promoting weight loss, and statin therapy instituted for all women with a QRISK2 score $\geq 10 \%$ for primary cardiovascular disease prevention, regardless of cholesterol measurement, and in accordance with NICE guidance. Such interventions are likely to reduce the number of cardiovascular events in the following 10 years and potentially improve overall survival in this population.

\section{Conclusion}

As well as underpinning its aetiology, obesity adversely impacts the diagnosis, management and survivorship of women with endometrial cancer. Abnormal bleeding in morbidly obese premenopausal women should be taken seriously as a 'red flag' symptom for cancer and investigated appropriately. The management of obese women with endometrial cancer should include optimizing co-morbidities, multi-disciplinary team input and use of minimal access surgery, wherever possible, to provide the best care. Alternative evidence-based treatments for endometrial cancer are urgently needed for premenopausal women and those medically unfit for surgery. Weight loss should be encouraged to reduce the risk of endometrial cancer in the prevention setting, and to improve overall and cardiovascular-specific survival in the post-treatment setting. Whether weight 
loss also offers opportunities for the treatment of obese endometrial cancer patients is an exciting but unexplored area of research. 


\section{$\underline{\text { References }}$}

1. Cancer Research UK. Uterine cancer statistics 2018 [Available from:

http://www.cancerresearchuk.org/health-professional/cancer-statistics/statistics-by-cancertype/uterine-cancer\#heading-Zero.

2. Crosbie E, Morrison J. The emerging epidemic of endometrial cancer: Time to take action. The Cochrane database of systematic reviews. 2014(12):ED000095.

3. Rahib L, Smith BD, Aizenberg R, Rosenzweig AB, Fleshman JM, Matrisian LM. Projecting cancer incidence and deaths to 2030: the unexpected burden of thyroid, liver, and pancreas cancers in the United States. Cancer research. 2014;74(11):2913-21.

4. Renehan AG, Tyson M, Egger M, Heller RF, Zwahlen M. Body-mass index and incidence of cancer: a systematic review and meta-analysis of prospective observational studies. Lancet. 2008;371(9612):569-78.

5. Crosbie EJ, Zwahlen M, Kitchener HC, Egger M, Renehan AG. Body mass index, hormone replacement therapy, and endometrial cancer risk: a meta-analysis. Cancer epidemiology, biomarkers \& prevention : a publication of the American Association for Cancer Research, cosponsored by the American Society of Preventive Oncology. 2010;19(12):3119-30.

6. Bhaskaran K, Douglas I, Forbes H, dos-Santos-Silva I, Leon DA, Smeeth L. Body-mass index and risk of 22 specific cancers: a population-based cohort study of 5.24 million UK adults. Lancet. 2014;384(9945):755-65.

7. Moore SC, Lee I-M, Weiderpass E, Campbell PT, Sampson JN, Kitahara CM, et al. Association of leisure-time physical activity with risk of 26 types of cancer in 1.44 million adults. JAMA Intern Med. 2016;176(6):816-25

8. Calle EE, Kaaks R. Overweight, obesity and cancer: epidemiological evidence and proposed mechanisms. Nature reviews Cancer. 2004;4(8):579-91.

9. Kaaks R, Lukanova A, Kurzer MS. Obesity, endogenous hormones, and endometrial cancer risk: a synthetic review. Cancer epidemiology, biomarkers \& prevention : a publication of the American Association for Cancer Research, cosponsored by the American Society of Preventive Oncology. 2002;11(12):1531-43.

10. Renehan AG, Frystyk J, Flyvbjerg A. Obesity and cancer risk: the role of the insulin-IGF axis. Trends in endocrinology and metabolism: TEM. 2006;17(8):328-36.

11. Nagamani M, Stuart CA. Specific binding and growth-promoting activity of insulin in endometrial cancer cells in culture. American journal of obstetrics and gynecology. 1998;179(1):612.

12. Ye J, Keller JN. Regulation of energy metabolism by inflammation: a feedback response in obesity and calorie restriction. Aging. 2010;2(6):361-8.

13. Modugno F, Ness RB, Chen C, Weiss NS. Inflammation and endometrial cancer: a hypothesis. Cancer epidemiology, biomarkers \& prevention : a publication of the American Association for Cancer Research, cosponsored by the American Society of Preventive Oncology. 2005;14(12):2840-7. 14. Dossus L, Rinaldi S, Becker S, Lukanova A, Tjonneland A, Olsen A, et al. Obesity, inflammatory markers, and endometrial cancer risk: a prospective case-control study. Endocrine-related cancer. 2010;17(4):1007-19.

15. Mackintosh ML, Crosbie EJ. Obesity-driven endometrial cancer: is weight loss the answer? BJOG : an international journal of obstetrics and gynaecology. 2013;120(7):791-4.

16. Campbell KL, Foster-Schubert KE, Alfano CM, Wang CC, Wang CY, Duggan CR, et al. Reducedcalorie dietary weight loss, exercise, and sex hormones in postmenopausal women: randomized controlled trial. Journal of clinical oncology : official journal of the American Society of Clinical Oncology. 2012;30(19):2314-26.

17. Parker ED, Folsom AR. Intentional weight loss and incidence of obesity-related cancers: the Iowa Women's Health Study. International journal of obesity and related metabolic disorders : journal of the International Association for the Study of Obesity. 2003;27(12):1447-52. 
18. Friedenreich CM, Neilson HK, Lynch BM. State of the epidemiological evidence on physical activity and cancer prevention. European journal of cancer. 2010;46(14):2593-604.

19. Schmid D, Behrens G, Keimling M, Jochem C, Ricci C, Leitzmann M. A systematic review and meta-analysis of physical activity and endometrial cancer risk. European journal of epidemiology. 2015;30(5):397-412.

20. Sjostrom L, Gummesson A, Sjostrom CD, Narbro K, Peltonen M, Wedel H, et al. Effects of bariatric surgery on cancer incidence in obese patients in Sweden (Swedish Obese Subjects Study): a prospective, controlled intervention trial. The Lancet Oncology. 2009;10(7):653-62.

21. Ward KK, Roncancio AM, Shah NR, Davis MA, Saenz CC, McHale MT, et al. Bariatric surgery decreases the risk of uterine malignancy. Gynecologic oncology. 2014;133(1):63-6.

22. MacKintosh ML, Derbyshire AE, McVey RJ, Bolton J, Nickkho-Amiry M, Higgins CL, et al. The impact of obesity and bariatric surgery on circulating and tissue biomarkers of endometrial cancer risk. Int J Cancer. 2018.

23. Soini T, Hurskainen R, Grenman S, Maenpaa J, Paavonen J, Pukkala E. Cancer risk in women using the levonorgestrel-releasing intrauterine system in Finland. Obstetrics and gynecology. 2014;124(2 Pt 1):292-9.

24. Iversen L, Sivasubramaniam S, Lee AJ, Fielding S, Hannaford PC. Lifetime cancer risk and combined oral contraceptives: the Royal College of General Practitioners' Oral Contraception Study. American journal of obstetrics and gynecology. 2017;216(6):580 e1- e9.

25. FSRH UK MEC. UK Medical Eligibility Criteria for Contraceptive Use 2016 [Available from: https://www.fsrh.org/standards-and-guidance/external/ukmec-2016-digital-version/.

26. Kitson SJ, Evans DG, Crosbie EJ. Identifying High-Risk Women for Endometrial Cancer Prevention Strategies: Proposal of an Endometrial Cancer Risk Prediction Model. Cancer prevention research. 2017;10(1):1-13.

27. Wise MR, Gill P, Lensen S, Thompson JM, Farquhar CM. Body mass index trumps age in decision for endometrial biopsy: cohort study of symptomatic premenopausal women. American journal of obstetrics and gynecology. 2016;215(5):598 e1- e8.

28. Funston G, O'Flynn H, Ryan NAJ, Hamilton W, Crosbie EJ. Recognizing Gynecological Cancer in Primary Care: Risk Factors, Red Flags, and Referrals. Adv Ther. 2018;35(4):577-89.

29. Wakefield Clinical Commissioning Group. Guidelines for GP Referral for Adult Routine MRI 2015 [Available from:

https://www.wakefieldccg.nhs.uk/fileadmin/site setup/contentUploads/Guidelines for GP Referra I for Adult Routine MRI v0.9.pdf.

30. Sundar S, Balega J, Crosbie E, Drake A, Edmondson R, Fotopoulou C, et al. BGCS uterine cancer guidelines: Recommendations for practice. European journal of obstetrics, gynecology, and reproductive biology. 2017;213:71-97.

31. Chung F, Yegneswaran B, Liao P, Chung SA, Vairavanathan S, Islam S, et al. STOP questionnaire: a tool to screen patients for obstructive sleep apnea. Anesthesiology. 2008;108(5):812-21.

32. Galaal K, Bryant A, Fisher AD, Al-Khaduri M, Kew F, Lopes AD. Laparoscopy versus laparotomy for the management of early stage endometrial cancer. The Cochrane database of systematic reviews. 2012;9:CD006655.

33. Walker JL, Piedmonte MR, Spirtos NM, Eisenkop SM, Schlaerth JB, Mannel RS, et al. Recurrence and survival after random assignment to laparoscopy versus laparotomy for comprehensive surgical staging of uterine cancer: Gynecologic Oncology Group LAP2 Study. Journal of clinical oncology : official journal of the American Society of Clinical Oncology. 2012;30(7):695700.

34. Janda M, Gebski V, Davies LC, Forder P, Brand A, Hogg R, et al. Effect of total laparoscopic hysterectomy vs total abdominal hysterectomy on disease-free survival among women with stage I endometrial cancer: a randomised clinical trial. JAMA. 2017;317(12):1224-1233. 
35. Wright JD, Burke WM, Wilde ET, Lewin SN, Charles AS, Kim JH, et al. Comparative effectiveness of robotic versus laparoscopic hysterectomy for endometrial cancer. Journal of clinical oncology : official journal of the American Society of Clinical Oncology. 2012;30(8):783-91.

36. Aarts JW, Nieboer TE, Johnson N, Tavender E, Garry R, Mol BW, et al. Surgical approach to hysterectomy for benign gynaecological disease. The Cochrane database of systematic reviews. 2015(8):CD003677. Ind T, Laios A, Hacking M, Nobbenhuis M. A comparison of operative outcomes between standard and robotic laparoscopic surgery for endometrial cancer: a systematic review and meta-analysis. Int J Med Robotics Comput Assist Surg. 2017;13:e1851.

37. Matsuo K, Jung CE, Hom MS, Gualtieri MR, Randazzo SC, Kanao H, et al. Predictive Factor of Conversion to Laparotomy in Minimally Invasive Surgical Staging for Endometrial Cancer. International journal of gynecological cancer : official journal of the International Gynecological Cancer Society. 2016;26(2):290-300.

38. Corrado G, Vizza E, Cela V, Mere L, Bogliolo S, Legge F, et al. Laparoscopic versus robotic hysterectomy in obese and extremely obese patients with endometrial cancer: a multi-institutional analysis. Our J Sure Oncol. 2018; Sep 15. pii: S0748-7983(18)31296-4.

39. Gehrig PA, Cantrell LA, Shafer A, Abaid LN, Mendivil A, Boggess JF. What is the optimal minimally invasive surgical procedure for endometrial cancer staging in the obese and morbidly obese woman? Gynecologic oncology. 2008;111(1):41-5.

40. Uccella S, Bonzini M, Palomba S, Fanfani F, Ceccaroni M, Seracchioli R, et al. Impact of obesity on surgical treatment for endometrial cancer: a multicenter study comparing laparoscopy vs open surgery, with propensity-matched analysis. Journal of Minimally Invasive Gynecology. 2016;23:53-61.

41. Crosbie EJ, Estabragh ZR, Murphy J, Ahmed AS, Slade RJ. Apronectomy combined with laparotomy for morbidly obese endometrial cancer patients. Surgical oncology. 2011;20(4):e187-93. 42. Nout RA, van de Poll-Franse LV, Lybeert ML, Warlam-Rodenhuis CC, Jobsen JJ, Mens JW, et al. Long-term outcome and quality of life of patients with endometrial carcinoma treated with or without pelvic radiotherapy in the post operative radiation therapy in endometrial carcinoma 1 (PORTEC-1) trial. Journal of clinical oncology : official journal of the American Society of Clinical Oncology. 2011;29(13):1692-700.

43. Nout RA, Smit VT, Putter H, Jurgenliemk-Schulz IM, Jobsen JJ, Lutgens LC, et al. Vaginal brachytherapy versus pelvic external beam radiotherapy for patients with endometrial cancer of high-intermediate risk (PORTEC-2): an open-label, non-inferiority, randomised trial. Lancet. 2010;375(9717):816-23.

44. Lin LL, Hertan L, Rengan R, Teo BK. Effect of body mass index on magnitude of setup errors in patients treated with adjuvant radiotherapy for endometrial cancer with daily image guidance. International journal of radiation oncology, biology, physics. 2012;83(2):670-5.

45. Podzielinski I, Randall ME, Breheny PJ, Escobar PF, Cohn DE, Quick AM, et al. Primary radiation therapy for medically inoperable patients with clinical stage I and II endometrial carcinoma. Gynecologic oncology. 2012;124(1):36-41.

46. Van Der Steen-Banasik E, Christiaens M, Shash E, Coens C, Casado A, Herrera FG, et al. Systematic review: radiation therapy alone in medical non-operable endometrial carcinoma. European Journal of Cancer. 2016;65:172e181.

47. Van der Steen-Banasik E. Primary brachytherapy as a radical treatment for endometrial carcinoma. J Contemp Brachytherapy 2014;6:106e12.

4․ de Boer SM, Powell ME, Mileshkin L, Katsaros D, Bessette P, Haie-Meder C, et al. Adjuvant chemoradiotherapy versus radiotherapy alone for women with high-risk endometrial cancer (PORTEC-3): final results of an international, open-label, multicentre, randomised, phase 3 trial. The Lancet Oncology. 2018;19(3):295-309.

49. Nagao S, Fujiwara K, Imafuku N, Kagawa R, Kozuka Y, Oda T, et al. Difference of carboplatin clearance estimated by the Cockroft-Gault, Jelliffe, Modified-Jelliffe, Wright or Chatelut formula. Gynecologic oncology. 2005;99(2):327-33. 
50. Horowitz NS, Wright AA. Impact of obesity on chemotherapy management and outcomes in women with gynecologic malignancies. Gynecologic oncology. 2015;138(1):201-6.

51. Gunderson CC, Fader AN, Carson KA, Bristow RE. Oncologic and reproductive outcomes with progestin therapy in women with endometrial hyperplasia and grade 1 adenocarcinoma: a systematic review. Gynecologic oncology. 2012;125(2):477-82.

52. Wan YL, Holland C. The efficacy of levonorgestrel intrauterine systems for endometrial protection: a systematic review. Climacteric : the journal of the International Menopause Society. 2011;14(6):622-32.

53. Walsh C, Holschneider C, Hang Y, Tieu K, Karlan B, Cass I. Coexisting ovarian malignancy in young women with endometrial cancer. Obstet Gynecol. 2005;106(4):693-9.

54. Kesterson JP, Fanning J. Fertility-sparing treatment of endometrial cancer: options, outcomes and pitfalls. J Gynecol Oncol. 2017;23(2): 120-24.

55. Falcone F, Laurelli G, Losito S, Di Napoli M, Granata V, Greggi S. Fertility preserving treatment with hysteroscopic resection followed by progestin therapy in young women with early endometrial cancer. J Gynecol Oncol. 2017;28(1):e2.

56. Hawkes AL, Quinn M, Gebski V, Armes J, Brennan D, Janda M, et al. Improving treatment for obese women with early stage cancer of the uterus: rationale and design of the levonorgestrel intrauterine device +/- metformin +/- weight loss in endometrial cancer (feMME) trial.

Contemporary clinical trials. 2014;39(1):14-21.

57. Derbyshire AE, Ryan N, Crosbie EJ. Biomarkers needed to predict progestin response in endometrial cancer. BJOG : an international journal of obstetrics and gynaecology.

2017;124(10):1584.

58. Nagle CM, Crosbie EJ, Brand A, Obermair A, Oehler MK, Quinn M, et al. The association between diabetes, comorbidities, body mass index and all-cause and cause-specific mortality among women with endometrial cancer. Gynecologic oncology. 2018;150(1):99-105.

59. Secord AA, Hasselblad V, Von Gruenigen VE, Gehrig PA, Modesitt SC, Bae-Jump V, et al. Body mass index and mortality in endometrial cancer: A systematic review and meta-analysis. Gynecologic oncology. 2016;140(1):184-90.

60. Crosbie EJ, Roberts C, Qian W, Swart AM, Kitchener HC, Renehan AG. Body mass index does not influence post-treatment survival in early stage endometrial cancer: results from the MRC ASTEC trial. European journal of cancer. 2012;48(6):853-64.

61. Rock CL, Pande C, Flatt SW, Ying C, Pakiz B, Parker BA, et al. Favorable changes in serum estrogens and other biologic factors after weight loss in breast cancer survivors who are overweight or obese. Clinical breast cancer. 2013;13(3):188-95.

62. Irwin ML, Fabian C, McTiernan A. Risk Reduction from Weight Management and Physical Activity Interventions. Advances in experimental medicine and biology. 2015;862:193-212.

63. Kitson S, Ryan N, MacKintosh ML, Edmondson R, Duffy JM, Crosbie EJ. Interventions for weight reduction in obesity to improve survival in women with endometrial cancer. The Cochrane database of systematic reviews. 2018;2:CD012513.

64. Humpel N, Magee C, Jones SC. The impact of a cancer diagnosis on the health behaviors of cancer survivors and their family and friends. Support Care Cancer. 2007;15(6):621-30.

65. Clark LH, Ko EM, Kernodle A, Harris A, Moore DT, Gehrig PA, et al. Endometrial Cancer Survivors' Perceptions of Provider Obesity Counseling and Attempted Behavior Change: Are We Seizing the Moment? Int J Gynecol Cancer. 2016;26(2):318-24.

66. Jernigan AM, Maurer KA, Cooper K, Schauer PR, Rose PG, Michener CM. Referring survivors of endometrial cancer and complex atypical hyperplasia to bariatric specialists: a prospective cohort study. Am J Obstet Gynecol. 2015;213(3):350 e1-10. 
67. Felix AS, Bower JK, Pfeiffer RM, Raman SV, Cohn DE, Sherman ME. High cardiovascular disease mortality after endometrial cancer diagnosis: Results from the Surveillance, Epidemiology, and End Results (SEER) Database. Int J Cancer. 2017;140(3):555-64.

68. Ward KK, Shah NR, Saenz CC, McHale MT, Alvarez EA, Plaxe SC. Cardiovascular disease is the leading cause of death among endometrial cancer patients. Gynecologic oncology. 2012;126(2):1769.

69. Kitson SJ, Lindsay J, Sivalingam VN, Lunt M, Ryan NAJ, Edmondson RJ, et al. The unrecognized burden of cardiovascular risk factors in women newly diagnosed with endometrial cancer: A prospective case control study. Gynecologic oncology. 2018;148(1):154-60.

70. Kitson SJ L, Sivalingam VN, Rutter MK, Crosbie EJ,. High prevalence of metabolic syndrome in women newly diagnosed with endometrial cancer. Gynecologic Oncology Reports (in press). 2018. 


\section{Figure legends}

Figure 1. Endometrial cancer incidence and mortality rates in the UK. The incidence of endometrial cancer has risen by over $50 \%$ in the last 20 years. Whilst this has resulted in an increase in the disease specific mortality rate, the widening gap between the number of cases diagnosed and deaths from the disease likely reflects the preponderance of good prognosis tumours associated with obesity.

Figure 2. Mechanisms through which obesity drives endometrial carcinogenesis. Excess adipose tissue is responsible for the creation of a state of oestrogen excess, hyperinsulinaemia and inflammation, which work in concert to upregulate gene transcription, cell proliferation and the accumulation of cancer-causing mutations within the endometrial cell. Abbreviations: $17 \beta H S D$ 17 $\beta$ hydroxysteroid dehydrogenase, ER oestrogen receptor, IKK IKB kinase, CXCR chemokine receptor, IL-6R interleukin-6 receptor, IR insulin receptor.

Figure 3. The levonorgestrel-releasing intrauterine system (LNG-IUS, Mirena) releases 20 micrograms of levonorgestrel per day directly into the uterine cavity, ensuring the highest level of the drug is delivered to the endometrial abnormality whilst minimising systemic side effects.

Figure 4. Photomicrographs of intra-uterine progestin-treated endometrial cancer showing a) residual endometrial neoplasia despite progestin treatment; and b) minor cytological atypia only with marked progestin effect.

Figure 5: Intra-uterine progestin plus sleeve gastrectomy for grade 1, stage 1a endometrial cancer with no myometrial invasion. Mary (who consents to her photo being shown) a) at baseline, weight $170 \mathrm{~kg}$; b) at 12 months, weight $120 \mathrm{~kg}$; c) MRI pelvis at baseline, showing bulky stage 1a EC (arrow); d) MRI pelvis at 12 months, showing complete radiological resolution (arrow), with complete endometrial response confirmed on biopsy. 
